CHAPTER 3

\title{
Business models beyond subsidies - which core competencies are needed?
}

\author{
Christoph Burger and Jens Weinmann
}

\subsection{Energiewende 1.0 - 3.0: matching phases of energy transition and business models}

As outlined in the introductory chapter, the energy transition is fuelled by two main drivers, which are reflected in the two main parts of this book.

The top-down drivers are typically governments or states - or regulatory institutions within these territorial administrative entities - that are striving for a reduction in greenhouse gases or want to promote certain industries and their technologies. Examples of countries, their policies and governance structures have been presented in the previous chapter.

In contrast, this chapter of the book is dedicated to the bottom-up drivers: individual businesses and start-ups that exploit niches within the new energy system to generate revenues by creating or joining new markets and platforms. They are emerging alongside the established players in the energy sector, in particular the electric utilities.

Liberalisation of the energy sector is generally the pre-condition for allowing these players to emerge. Liberalisation (of certain parts of the value chain) creates opportunities for trading electricity and natural gas on wholesale markets,

How to cite this book chapter:

Burger, C. and Weinmann, J. 2020. Business models beyond subsidies - which core competencies are needed?. In: Burger, C., Froggatt, A., Mitchell, C. and Weinmann, J. (eds.) Decentralised Energy - a Global Game Changer. Pp. 177-260. London: Ubiquity Press. DOI: https://doi.org/10.5334/bcf.k. License: CC-BY 4.0 
with all types of financial instruments being offered by multiple players. However, a bottom-up movement is also possible in country settings that still favour a fully regulated configuration of the electricity supply. For example, governments can also demand/require that a certain share of a load-serving entity's energy supply is derived from renewable sources (for a discussion, see also Kieffer \& Couture 2015). These utilities could then issue tenders to other players and outsource the ramp-up of renewable capacity, with most closely following the existing model of independent power producers (IPPs), which supply certain amounts of energy, typically in long-term contracts with utilities or the government. This model of transformation functions via command-and-control rather than market-based mechanisms. California versus New York state would be classical examples of these two differing approaches.

Whereas regulatory policies, implementation, and rollouts may differ after the electricity market is liberalised, the move towards decentralisation typically encompasses three phases, which we call Energiewende 1.0, 2.0, and 3.0, or Phase I, Phase II, and Phase III (see Burger \& Weinmann 2017 in the Harvard Business Review for further details). In technical terms, they can roughly be associated with a deployment of 'new' renewable energies with a supply share of less than 10 per cent in Phase I, when renewables still represent a niche of the electricity supply. In Phase II, their contribution rises to 10 to 40 per cent, and they become a major player in the supply portfolio. Phase III is characterised by an aggregate renewable-energy supply of more than 40 per cent, when they can be characterised as a dominant player by an aggregate contribution of more than 40 per cent and renewable energies as the dominant player (Baumgartner 2017).

This categorisation is only valid for the 'new' renewable-energy sources, in particular wind, solar, and biomass. For example, the United Kingdom meets some of its renewable targets by co-firing large, old coal stations with biomass. By contrast, countries with a high share of large-scale hydropower, such as Brazil, Norway, and Paraguay, do not enter this classification as Phase III countries despite the fact that renewable energies play a dominant role in electricity supply - because the supply structure is based on centralised operations and control of the assets. ${ }^{51}$

Each of the three phases brings its own opportunities and challenges for policy makers as well as corporate players such as utilities and start-ups, as will be discussed in greater detail in Chapter 4.

${ }^{51}$ Hydropower has been in use for more than a century to produce electricity, and it does not feature the decentralised geographical pattern of 'new' renewable energies. In terms of structural similarities, in particular with regards to the financing and complexity of construction, offshore wind farms could be compared most closely to a conventional hydropower dam: Both require larger players with a strong financial endowment or backing by investors to provide the high levels of investment up front. 
- Phase I (Energiewende 1.0): in Phase I of the energy transformation, countries explore opportunities to incentivise the deployment of renewable (non-hydro) energy sources. Start-ups benefit from public funding for the rollout and provide services. Owners of residential rooftop photovoltaic (PV), bioenergy villages, and also energy associations that operate wind turbines are at the heart of a 'civic power' movement, in which assets are owned by private individuals, without a utility being involved in the operation of the plants. In parallel, small and medium-sized enterprises (SMEs) and some power companies are investing in and deploying renewables.

- Phase II (Energiewende 2.0): Phase II of the energy transformation is characterised by civic power emerging as a third force in the market, complementing electric utilities and corporate new entrants in the energy sector. Civic power is one of the reasons why the decentralised energy revolution may become a 'global game changer' - it shifts the responsibility of electricity supply back to the citizens of a country.

During Phase II, platforms are created that coordinate supply and demand or offer services such as aggregating existing capacity or loads (for peak shaving). When multiple atomised actors are involved, data has to be gathered and analysed. Individual owners of assets may not be sufficiently knowledgeable to deal with the complexities of the energy system, and they outsource that expertise to companies that specialise in providing these services.

Regulators start modifying the initial incentive systems in Phase II. A continuation of directly or indirectly subsidising renewable energies is often countered by public opposition because of the heavy burden for ratepayers.

Utilities adapt to the new market environment by reorganising their activities, as it happened for example in Germany, when incumbent utilities E.ON and RWE split their traditional thermal generation and trading units from their distribution, renewables and service-oriented business lines, and later merged these two new entities.

- Phase III (Energiewende 3.0): Phase III of the energy transformation, or 'Energiewende 3.0', has yet to be seen in any country. Non-hydro renewable energies will become the major player in the supply structure. The marginal costs of renewable energies such as wind and solar are practically zero, so there will be a resource abundance at certain times, and extreme scarcity (and high prices) at other times. Hence, storage will become a major issue for policy makers.

The electricity supply industry will be forced to leave its roots as public infrastructure service and transform into truly private businesses, offering customised solutions for each consumer, while independent system operators or private transaction platforms take over responsibilities of grid control. As with many other aspects of our lives, energy may become an individualised choice, with each of us determining the amount of risk we are willingness to take. The customer proposition may become central in this phase but it will not necessarily mean that customers will become active 
beyond choosing a proposition they like. Energy will, of course, remain a public infrastructure service, but the state's involvement will shrink, as happened in the telecommunications and aviation sectors.

\subsection{Start-ups pave the way towards a new energy system}

Compared to the 'safety and reliability' paradigm that has dominated the mindset of executives at electric utilities until very recently, start-ups typically have a different mentality and culture. A willingness to take risks and to 'pivot' which means a radical change in the business model - are essential ingredients in their trajectory towards success. Large companies have started complementing their traditional research and development units with external input to increase diversity and the spectrum of potential future business options. They acquire smaller companies with new ideas, for example Centrica in Great Britain, participate in accelerators, establish incubators and venture capital funds, foster a culture of intrapreneurship, that is, internal entrepreneurship, and are (slowly) changing their business models - from selling a commodity to becoming a provider of integrated service solutions.

As in many other industries, the electricity supply industry benefits from innovations and unconventional ideas being brought to the market by start-ups, founders, and entrepreneurs. The focus of the interviews used in this part is, hence, on the insights generated by their experiences.

The start-ups with whom the interviews were conducted have been selected to mirror the changes that are taking place in both industrialised and developing countries. Start-ups in developing countries may have completely different business models than start-ups in industrialised countries. This is because the former use decentralised energy generation to complement the existing grid infrastructure in areas where grid connections are not established, whereas decentralised energy in industrialised countries is a substitute and replacement of existing supply (and respective institutional) structures.

Furthermore, they have been chosen as representative examples of the three phases of the energy transformation described above.

One case study of business models during Phase I of the energy transformation is Envio Systems (no. 1), a Canadian start-up that offers a low-cost solution to enhance the energy efficiency of existing commercial buildings. Moving towards a partially autonomous system with a larger share of renewable, intermittent energy, Timo Leukefeld (no. 2) has developed a commercial solution for an (almost) energy-autonomous house, whereas Entelios (no. 3) has been one of the first providers of demand response services in Europe. For most industrialised countries, Phase III of the energy transformation is a vision, a future perspective, but in the context of isolated, rural areas in the developing world it is factual reality. The business models of the three start-ups SOLshare (no. 4), Mobisol (no. 5) and Solarkiosk (no. 6) offer alternatives to the connection to 


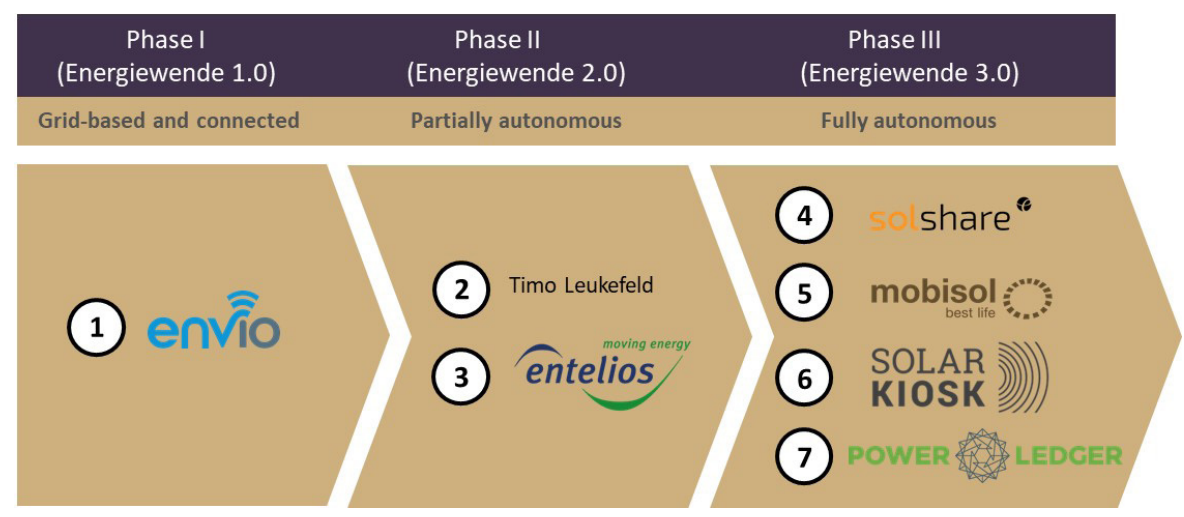

Figure 20: Classification of interviews according to phases of the energy transformation.

Source: Authors' contribution.

the central grid. By contrast, Australian start-up Power Ledger (no. 7) is a pioneer in peer-to-peer trading and Blockchain-based decentralisation of power supply in highly developed urban and suburban settings.

Innovators test new business models. Only a few survive, others inspire new ones. Scaling becomes important, and this might be a reason why many disappear. Since some of the interviews have been conducted, substantial changes in the business models or career paths of the interviewees have taken place. Some of the startups have filed for insolvency, others have been acquired by larger competitors. All interviews must therefore be interpreted as snapshots of their situations of the world at a certain point in time. Despite these developments, the interviewees kindly agreed to authorise the publication of the interviews after providing updates on their ventures before the manuscript was completed and submitted to the publisher.

\subsubsection{References}

Baumgartner, D. (2017), How to integrate a high share of renewables into the grid? HEC-ESMT Energy Course. C. Burger and J. Weinmann. Berlin, Elia Grid International.

Burger, C. \& Weinmann, J. (2017), The 3 stages of a country embracing renewable energy, Harvard Business Review. Retrieved February 11, 2019, from https://hbr.org/2017/04/the-3-stages-of-a-country-embracing-renewableenergy, accessed 11 February 2019.

Kieffer, G. \& Couture, T. D. (2015), Renewable energy target setting. Abu Dhabi: IRENA. 


\title{
3.3 Envio Systems: redefining building efficiency - Envio Systems targets an untapped legacy market
}

\author{
Interview with Reza Alaghehband, co-founder and CEO at Envio Systems, \\ on August 26, 2016
}

Envio has developed an end-to-end commercial building management system capable of turning any existing commercial building into a sophisticated, fully autonomous Smart Building. The company's intelligent controls, digital infrastructure and web-based management platform can be easily and affordably integrated into any type of facility, regardless of its size, age, or sophistication level. According to the start-up, this is a breakthrough solution that affordably enables the AI (artificial intelligence)-powered, fully autonomous management of commercial buildings without the need to replace any existing infrastructure. It pays for itself from the energy savings in less than three years, which is a fraction of the cost of existing solutions. The systems create smarter facilities that operate using 20-70 per cent less energy (Envio Systems 2018).

\subsubsection{Technology and business model}

What are the barriers preventing 87 per cent of all commercial buildings from adopting advanced automation systems? The answer is simple: the costs heavily outweigh the benefits. We have developed our system as solution to this question.

With our system we wanted to overcome three major challenges: First, how can we eliminate structural complexity, which would require a high level of expertise to operate or troubleshoot? We decided to supply a pre-wired, easy-to-deploy set of systems ready for installation. Any electrician globally can install and test it using our simple app. It reduces the high cost of installation by enabling a wireless plug and play set-up. The second challenge was compatibility: How do we make it interoperable with the vast majority of systems? We developed adaptive and remotely configurable hardware flexible enough for every scenario. Third, how can we minimise customisation and circumvent an advanced configuration required for each facility? We achieve this with self-programming, commissioning, and learning devices configured via templates over the web.

\section{Technology}

The system we have developed is comprised of three key components. The first is the 'Cube', a plug and play IoT (Internet of Things) controller that 
universally connects to any legacy device in a building (light switches, thermostats, boilers, chillers, fans, pumps, valves, metres) to enhance them with bi-directional communication, web connectivity, and enable building-wide interoperability.

The second component is the Envio Gateway, which is a translator between communication protocols and legacy systems as well as a bridge between the Cubes to the cloud and back.

The third is our web-based platform, which collects, analyses, and visually displays all components and also hosts our algorithms. This is the key component, in that it utilises real-time and historic information to determine the optimal setting for every single component, building-wide. Then it sends the settings back to the building for each Cube to execute.

How can we consolidate proven energy-efficiency functionalities that every building needs while preparing them for the future? Where can we create the highest dollar-for-dollar value? How can we integrate everything into one device? Instead of having redundancy in the hardware of our buildings, which increases costs and makes them less financially viable, we wanted to combine them and use one device with the advancements in processing power to collect all that information. We wanted to be able to make active decisions and communicate with various building systems using the existing infrastructure. Rather than ripping things out and putting new equipment in, we simply integrate the device with the existing equipment, making it smarter and helping it to operate more efficiently.

Commercial buildings operate similarly to factories, ensuring that the people inside are comfortable by managing climate, lighting, and ventilation. Factories are only efficient when fine-tuned for consistency. The difficulty is that, in commercial buildings, there are dozens of completely unpredictable variables such as occupancy, outdoor temperature, heat loss, sunlight, and efficiency losses, which are unique to each building and constantly change. Using machine learning, our technology automatically learns and adapts to each building.

Our core IP is built right into the intelligence. Based on the sensor information that is located around the area, the systems decide on what is being told to the radiators, the fans, etc., unless we give them other instructions based on additional information coming from all the sensors we have in the area. When rooms are occupied, in most cases we allow people to have full control over what is going on, depending on how they like their environment. But once they leave, the majority of the systems will continue to heat and light that room and have the same level of ventilation entering the building and the room. We prevent that, and that is how we go about saving energy.

One of the first things we do is to implement our system within the building. With every Cube that we equip, we have about six sensors to monitor that area. In every room with a Cube, we are able to track the rate of heat loss and gain, 


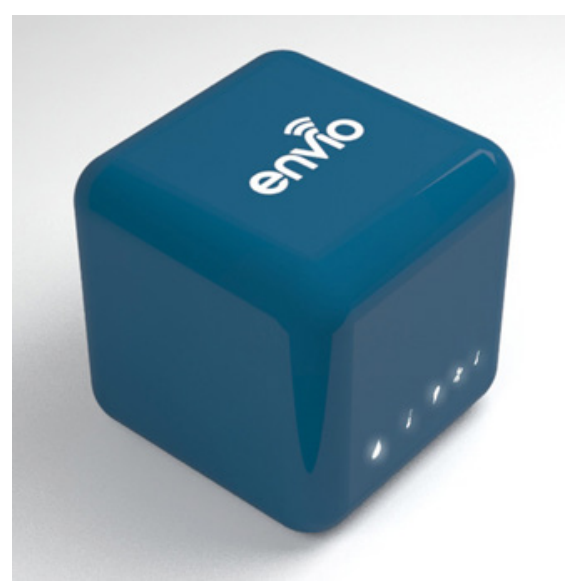

Figure 21: Envio Systems' Cube.

Source: Envio Systems (2017).

the efficiency of the fans, and the ventilation and heating system. We are able to tell what strategies and products would be most beneficial in which areas, and where they should target first. It is never a shotgun approach to put everything in because not every installation is going to give you the returns that you need. Our system diagnoses where the most energy is being lost and why. Using that information, one can make much more intelligent decisions. We recommend to the building owners and operators the best dollar-for-dollar investment.

Our Cubes are also equipped with a $\mathrm{CO}_{2}$ sensor for demand-control ventilation. That is probably one of the highest cost components within our system for each system that we implement, but it pays for itself within that period, so it is extremely beneficial to have.

We are very satisfied with the functionality and the payback of our system. In most scenarios, we are offering a cheaper alternative to what our customers would normally be implementing. Energy conservation and efficiency in commercial, industrial, and even residential buildings is a very straight-forward and repeatable process. First and foremost, you need to measure and understand what is going on in there before you can even make any decisions. If you are just looking at a bill, you do not know whether the energy consumption primarily came at the beginning of the month, at the end of the month, or even if it is an annual total. Time-based information is needed to understand what is going on within buildings. Once you have that information, you can prioritise which features you want to implement. Many companies come in with technologies that just sense information.

For me, that is a giant waste of money, because sensing information is great. But I have found in 99 per cent of the cases that, unless there is a major flaw 

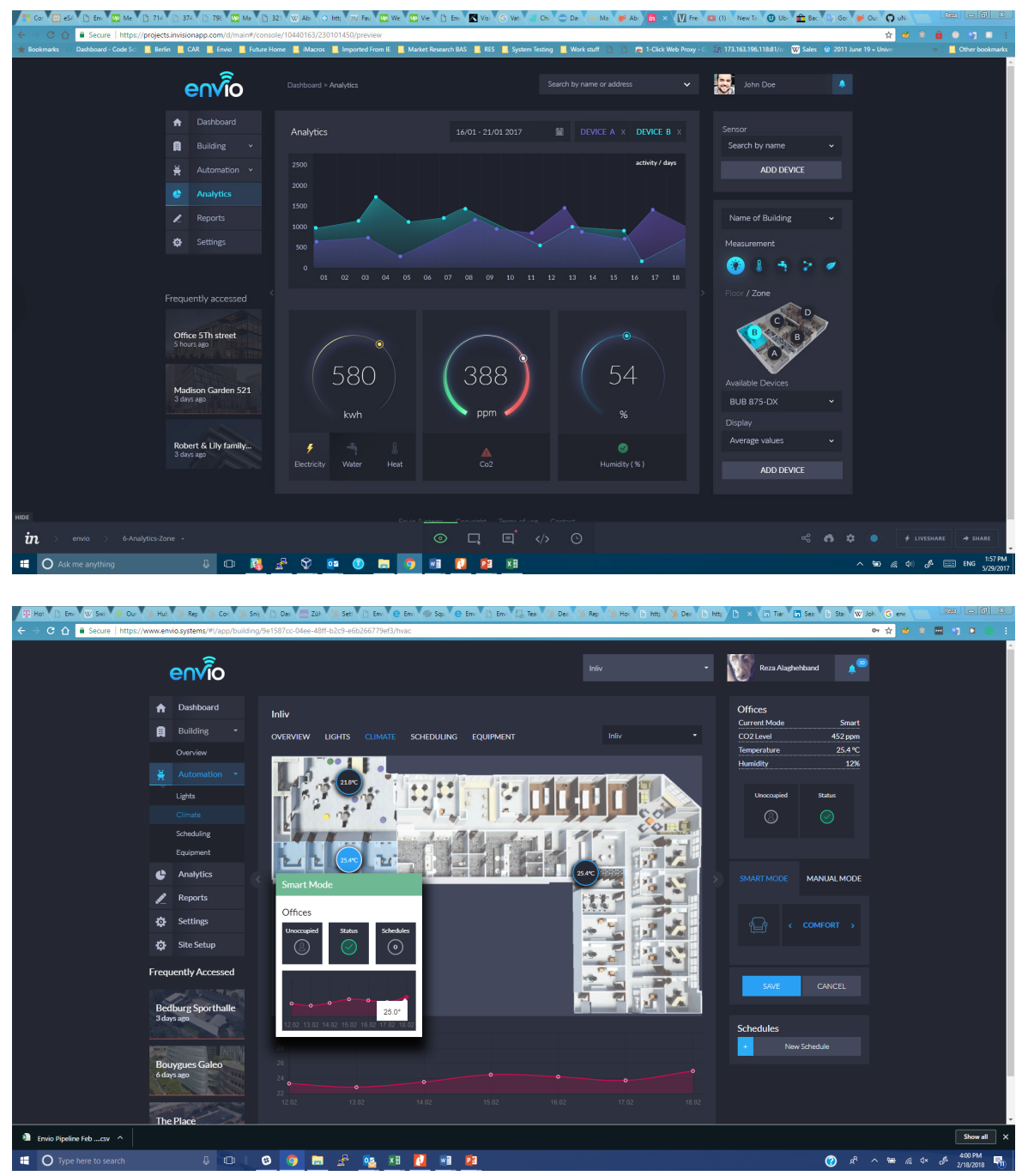

Figure 22: Envio Systems' BASE dashboard.

Source: Envio Systems (2017).

in the operations that they are completely missing, nobody is going to go and make the small adjustments that are continuously needed. The building may not have the capability for someone to make those small adjustments. But if you were to combine and utilise existing infrastructure and take the information and do something with it autonomously, it would actually require someone to take that part on. It brings people on board in a more active way because everybody loves the technology: It is fascinating to see everything going on, 
and it is great to get people engaged with a system that is not difficult to use. Bringing together various parts and various functionalities under one platform gives users the opportunity to have something like an operating system for their building and an incredibly valuable asset.

One should first install the energy metering system along with sensors and controllers. This is because there are basic functionalities that buildings older than 20 years do not have, which we implement in order for them to operate more energy-efficiently. Those are a required package. The energy monitoring system needs to be incorporated, otherwise we do not know what effect, say, turning down the fans is having in real time. In our package, we encompass energy monitoring. We know where the baseline is for the average commercial building, and we know the energy intensity per square foot/metre that should be used within these buildings. If a building's usage levels are above that, one knows that something is wrong. Around 40 per cent of energy in buildings is wasted, somewhat analogous to marketing: 50 per cent of your marketing budget is wasted; the problem is to find that 50 per cent. Instead of spending a lot of money and time putting in one solution to fix one problem, you incorporate multiple solutions into one device using all the same intelligence and share that intelligence with all the other rooms, then you have a synchronous system that looks not just at one part of the building but at the building as a whole. Implementation costs are lower because of the savings they produce. It would not make economic sense to buy separate sensors for the lights and HVAC if I installed current transformers (CTs) to measure and monitor electricity consumption. None of that would get a payback for you because of the redundancies in the hardware and the costs for manufacturing every single device. Sensors are incredibly cheap if you plug all of them into one device.

If consumers allow for active demand-side management, they will get benefits from it. But it also opens up a market that they are not fully in yet and have not yet figured out how to penetrate.

Our system does not need to be connected to the grid. If a building has a decentralised energy system, one of the most valuable features is being able to control it so that the owners can balance the load.

It is not a challenge to create and develop a system like ours. The challenge rather is backward compatibility with existing systems and understanding how to integrate them. We have a competitive edge in analysing all the information and having the building adjust to operating in the most energy-efficient way. It is no longer about simple control strategies. We are able to detect how much energy is being used by fans and the ventilation system, and we can control the pumps and the hot water boiler temperature. Over time, all of these systems become inefficient at different rates. We can determine the most efficient solution - increasing the speed of the fan or adjusting the hot water temperature - by applying intuitive and real-time operations and adjustments. 


\section{Business model}

There is an opportunity for savings in every single building. In trying to make the solution viable, one has to determine the potential for reducing energy. If you want it to happen during a certain payback period, what would be the desired pricing model that fits with the reductions? The biggest component of selling energy efficiency is really the pricing model, understanding energy costs and prices, looking at the energy statistics and analysis, and generating energy savings.

We started in one of the markets with the lowest energy prices, almost globally, which was Calgary, Alberta, in Canada. The concept was that if we succeeded in making our system economically viable there, we could make it viable anywhere in the world. Alberta is not a very progressive province in terms of utility rebates, so we did not even have that luxury to fall back on if we made a business case. The cost savings had to be strictly from the energy savings that we produced.

Having worked for years within the industry, I know that there is a finite payback period of the systems and solutions implemented in terms of energy efficiency and conservation. We must meet that threshold. Any measure above that threshold may be realised, but it goes towards next year's budgeting, or the year after, which creates a much longer sales cycle. That happens to be one of the killers of the existing business model. There is no chance for generating revenue to finance business operations so fast.

If you are targeting the B2B market, no matter how sexy it looks, the bottom line is what matters for them. As a general rule of thumb, investments should pay off over a period of 36 months. Sometimes it is less, but if it does not provide some payback within 36 months, it is usually a very, very difficult proposition to sell. You have to figure out the savings and work backwards to figure out your pricing model.

Simplicity is the key to our business model. I have been working on this business model for about six years now. It has evolved over time and adapted. The original business model was a shared savings approach. It failed because nobody would touch it. There were tremendous measurement issues. We thought our system would overcome that because we were putting sensors and measurement devices everywhere to detect exactly how much we were saving. However, what happens generally is that one has no control over what the customers install in their buildings over time, and it becomes too complicated.

We are currently conflicted about our pricing model, and we may go in a different direction. Together with a very large utility partner, we are creating something incredibly disruptive for the market. Instead of us charging for the controllers, we are looking at hardware-as-a-service model, whereby clients simply pay on a monthly basis for us to reduce their energy costs.

We normally have recurring revenue. We can reduce the cost of the hardware to a minimum. If we increase the software service revenue to about 75 per cent of the savings we are generating, we can provide the hardware free of charge to 
rapidly capture market share. We can go to clients and offer them hardware and software at little to no cost, with no initial capital investment required. It will help them to reduce energy costs without any upfront costs and helps to resolve the value dilemma - the owner not being the operator.

The partnering utility derives benefits from being able to manage buildings more intelligently and to communicate with the interior devices of the building, bringing all these systems together and connecting them.

We do our pricing model by market. In Canada we have much lower pricing. We do it in 500 Canadian dollars because the utility rates and energy rates are much lower there. We increase our pricing model in markets where we have the opportunity for, say, utility rebates to increase gross margins.

We charge $€ 15$ per controller per month. On the platform, our customers can monitor how much energy they save. For example, if customer spend US $\$ 18,000$ per month for our controllers, they may save US $\$ 25,000$ per month in energy costs.

We would offer this service at a lower rate in places such as Calgary, but it would be lower on our list of preferred markets. In Canada, we would first target the province of British Columbia, where the government offers a rebate of 50 per cent.

\subsubsection{History and organisation}

We are currently employing about 14 people now. We add roughly one or two people per month. Realistically, within the next 12 months, we will need to have a total of 35-40 people. We retain our employees by having them be invested in the company so that it is not so easy to lure them away. The majority of our new hires will be working in the area of engineering and research and development. We will change the industry with our next product.

Our company will be set up in a decentralised way. If we are too centralised, we cannot react and manage appropriately. Our servers will be located wherever we are on that continent. Due to legislation, we have to make sure that our European servers are within Europe. As our data is highly secretive, it has to be secured. We will most likely have our centralised R\&D facilities in Berlin. Our goal is to create an entire platform that other hardware systems can integrate into. We want to overcome the problem of everybody designing their own user interface, and thereby overwhelming clients.

\subsubsection{Scaling and cooperations}

\section{Scaling}

We have developed the first Building Automation technology, which is designed for rapid global scalability. Within the building controls industry, 
you will find that most companies are regional except for the big four (Siemens, Johnson Controls, Honeywell, and Schneider Electric). This is due to the requirement of having specialised installers, who must go on site to install, configure, and commission the systems. Our solution can be installed by the building owners' existing electrical contractors, and the set-up and configuration is either automated or completed remotely. We continuously monitor each sensor and controller for failures. In case of such an event, they can quickly be swapped out and will automatically download the previous unit's programming within seconds.

Our focus is on where we can have the most impact in terms of profitability, so we target the key markets first, the ones with higher energy rates. In Europe, electricity rates are significantly higher than in Canada. California, New York, and almost any place on the US east coast is available because there are fewer natural resources. As people move more towards renewable energies, energy costs become significantly higher.

There are tremendous opportunities available in developing countries because scarcity creates an increase in price, and most of those countries are just deploying diesel generators to power things, which is much more expensive than the costs for transmission lines and electricity here. Our system would allow for a more streamlined management of electricity grids, which would prevent blackouts and brownouts. Utilities could manage the grid better by simply turning down devices, which is a more granular control of energy consumption.

\section{Cooperations}

I recognised that we needed a partner a long time ago. The challenge was having people understand our business model, understand the industry, and say: 'Wowthat is very different from what is out there!' Except for those entrenched in the industry, people were not able to differentiate how we were different from Nest. It took a very long time to overcome that, and explaining and clarifying our value proposition was a challenge. We have a very long time to refine our business model. Gridpoint essentially bought three companies and tried to glue them together to create a product. It is a beautiful business model, except when overhead costs are so high that a company has to borrow hundreds of millions of dollars to keep operations going. Gridpoint did not realise how slowly the scaling process advances. As they move forward, they need to bring on the right team members and go to the right market. Unfortunately, they got to a point where investors became a little nervous about how deep they were going, so they were purchased.

The leading utilities know that they are behemoths and that they move incredibly slowly. They know they have to disrupt their business model before a company like us comes and does it before them. They have to be proactive rather than reactive. Major utilities understand that their business model is going to be dead probably within the next 10 to 20 years. It will have a significant impact, 
with big power stations just closing down due to government mandates, as well as decentralised energy taking a huge chunk of revenue away from them. They need to adjust their business model in order to stay alive.

Our biggest hurdle will be distribution. The utility would help us with distribution as well as logistics and operations. One of their biggest assets is information. They know how to scale and to deploy infrastructure almost better than any existing company. They know the market and who the largest energy users are. They can actually access their data and verify which buildings are most likely to be energy-inefficient and determine where to go with that information and how they can help them. If we establish a partnership with them, they can bring on the manufacturing side that we need support with and they can help us with the marketing and branding - they know the industry. They can provide some of their best engineers to us so that we can find out how to really take advantage of the data and the implications of that. They can provide us with resources that we cannot acquire fast enough to scale as needed.

We are also in talks with an elevator company. The reason why we would like to cooperate with them is that we would like to have the resources to service our clients. We would work with them as operators of our devices, whereas the cooperation with the utility would be mainly focussed on sales.

Most owners own more than buildings and have diverse portfolios. There are companies that own dozens, if not hundreds of buildings. We are currently working with a major property management company that is in a publicprivate partnership. Their role is to retrofit all city buildings to make them more energy-efficient to achieve the 2020 goals. Our first project together with them was a school, and it has already been implemented.

We are continuously looking for partners with whom we can easily bring onto a very sophisticated interface and exchange information between various systems to help the owners operate their buildings more efficiently. We are looking for apps. We are looking for solar companies or storage companies as partners. We want to help in getting devices to hit the market faster. It is a long process to establish a product in the market. With our support, we can direct these companies to the right clients.

\subsubsection{Market outlook and competitive environment}

We are different from other providers such as Nest, which produces devices for residential applications. When you do a residential application in one location, you are missing out on all the information around you. You are making a decision for maybe not only one specific room, but for the entire living area upstairs, downstairs - which is a terrible way of going about it because you do not have sample data from other areas. Every single one of our Cubes is placed in various rooms to control that zone and that area, based on the information it 
is getting rather than assuming that the one single room with the sensor is the norm within that building.

When we work in commercial buildings, we usually have access to the ventilation system and ventilation controls, which provides a huge savings opportunity for us, just with being able to adjust ventilation based on the amount of carbon dioxide in there. Nest's focus is not energy savings, but rather it is a business strategy. They are not selling their hardware based on the fact that their customers will save a certain fixed amount. Rather, they sell it to give customers control - it gives you a little bit of information, and it looks very sexy. It is a consumer product.

\subsubsection{Interviewee biography}

Reza Alaghehband is a serial entrepreneur originally from Vancouver, British Columbia, now residing in Calgary, Alberta. He enjoys the challenge of disrupting the status quo through innovation and unique strategies. He possesses a Bachelor of Commerce in Entrepreneurial Expertise from Royal Roads University. Reza has been a featured presenter internationally at universities, industry conferences, and multinational organisations discussing technology, entrepre-

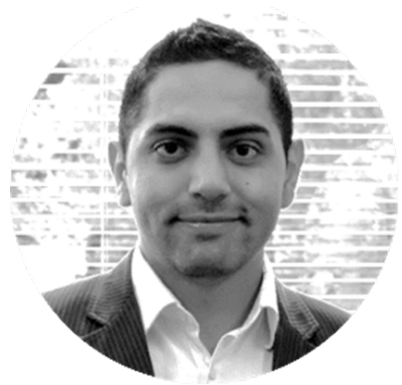
neurship, and innovation. Reza was the youngest member to be accepted into the Service Core of Retired Executives (SCORE) in the organisation's history.

He has been successfully founding companies in multiple industries, focussing primarily on materials engineering, renewable energy, and most recently energy conservation as the founder and CEO of award-winning Envio Systems, Inc.

\subsubsection{References}

Envio Systems. (2018), Smart buildings simplified. Retrieved February 10, 2018, from https://enviosystems.com/, accessed 10 February 2018. 


\title{
3.4 Timo Leukefeld: a business model for an energy- autonomous house without subsidies
}

\author{
Interview with Prof. Timo Leukefeld, TU Freiberg, on April 6, 2017
}

Can a business model based on energy autonomy also be viable for industrialised countries? Germany, for example, has one of the most reliable electricity systems in the world, with the System Average Interruption Duration Index (SAIDI) typically hovering around two minutes per year, and a 100 per cent electrification rate. Yet, Timo Leukefeld, lecturer at the Technical University Bergakademie Freiberg in the German state of Saxony, is promoting an energy-autonomous house that produces its own heat and power - including the electricity for an electric car - with solar power.

\subsubsection{Technology}

I am a lecturer at the Technical University Bergakademie Freiberg. Together with my team, I have developed a financially viable and commercially successful concept for an energy-autonomous house.

I live and work in an energy-autonomous house that offers around 160 square metres with a solar thermal rooftop collector of 46 sq. m), photovoltaic (PV) panels measuring $58 \mathrm{sq} . \mathrm{m})$, a 9300 litre long-term water storage tank, and an electric battery with a capacity of $56 \mathrm{kWh}$, based on lead technology. My consulting practice and I were in charge of the design of the energy-related installations.

Staff from the Technical University of Freiberg examined the energy performance of the building over the last four years with 190 sensors and observed that the house reached almost 100 per cent electric energy autonomy, including the supply for charging an electric vehicle. In thermal supply for heating and warm water, 70 per cent autonomy was achieved. The remaining 30 per cent of additional heating requirements could be met by using 3 cubic meters of fuelwood in the winter, which led to a carbon-neutral energy balance all year around.

The outer protection layer of my buildings fulfils similar quality standards as a so-called KfW 55 house, which uses 55 per cent less primary energy than a standard house. With the solar thermal system and PV panels, energy costs of a prototypical passive house can be further reduced - by more than twothirds. The electric vehicle can be charged 10 to 11 months per year with locally produced electricity. Only in December and January must additional electricity be purchased from the energy supply company to charge the car's battery. These buildings achieve very high levels of energy autonomy, and the costs for 


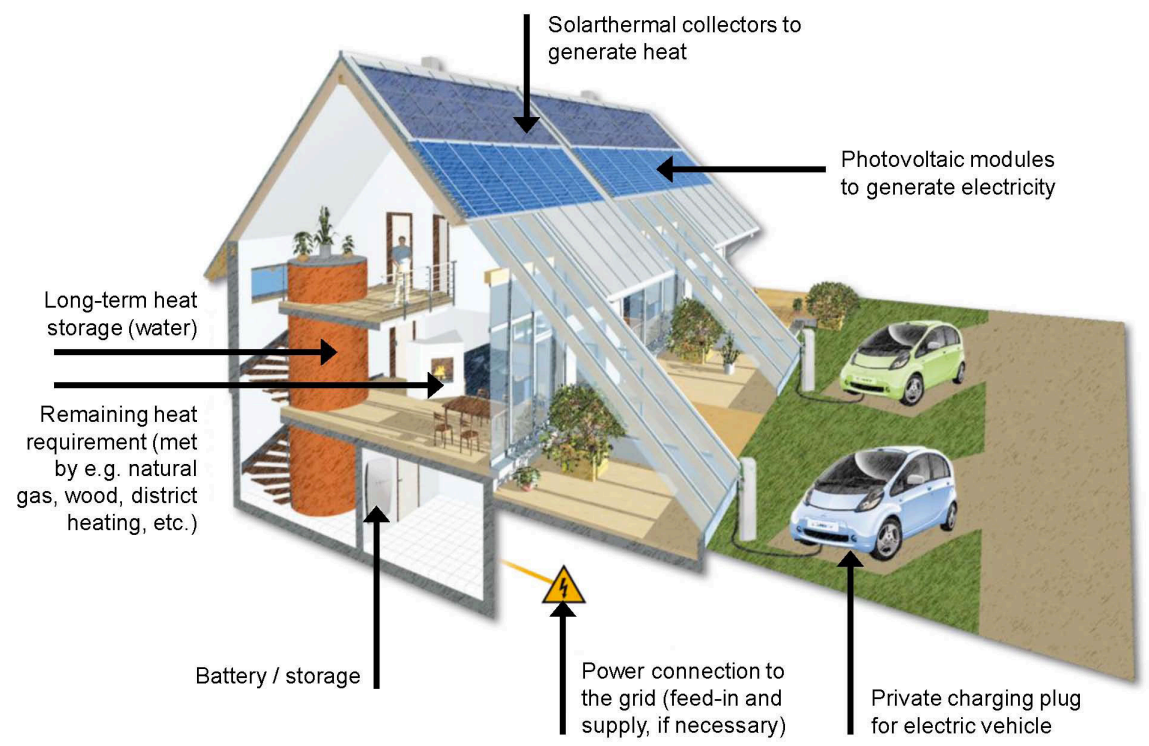

Figure 23: Features of Timo Leukefeld's energy-efficient houses.

Source: Leukefeld (2018).

energy services - including individual passenger transport - are significantly lower than the energy costs of 'passive houses', which achieve the bulk of their energy savings from passive sources, such as the heat produced by humans or technical devices.

The storage battery of my model house becomes part of a Smart Energy Grid with the objective to positively contribute to network stability and earn money from grid-balancing services. Instead of sending excess renewable power supply to neighbouring countries for free, or even paying money to get rid of the electricity generated by intermittent renewables - often accompanied by negative prices on the German wholesale market - the available electricity can be locally used inside the house for heating up the water in the reservoir. I favour lead batteries over lithium-ion batteries because they are still more economical. One can purchase lead batteries for $€ 250$ per kilowatt hour (kWh) of storage capacity. By contrast, in our current projects we purchase lithium-ion batteries at a price, depending on the size of the battery, of around $€ 700$ to $€ 800$ per $\mathrm{kWh}$, including value-added tax and installation.

Of course, when lithium-ion batteries will become cheaper in the near future, I would favour that technology, because those batteries have a longer life-time and better performance, and generally are better suited for electric mobility. 


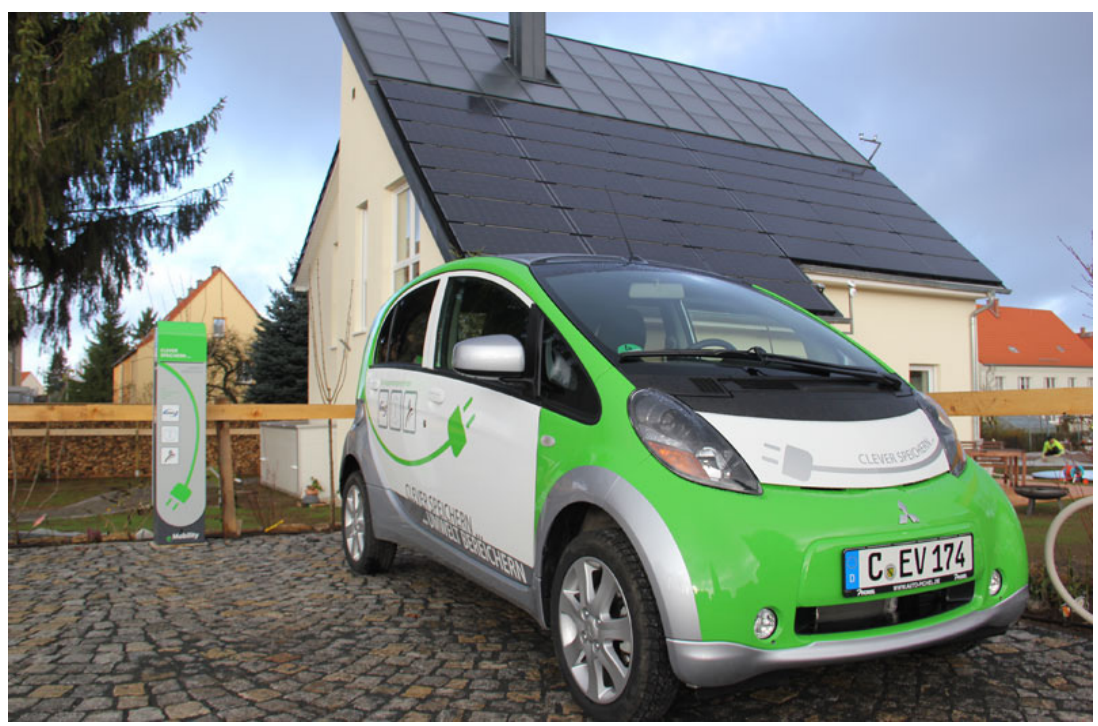

Figure 24: Energy-autonomous, single-family house in Freiberg.

Source: Leukefeld (2018).

According to my assessment, the battery of the associated electric vehicle is too small to participate in the balancing market. By contrast, most of the electric vehicles that are currently available have batteries with a capacity of 12 $\mathrm{kWh}$, but to effectively participate in the market they should contain a storage capacity of at least $50 \mathrm{kWh}$.

My team has expanded its planning approach from a single-family home to a residential building with seven flats. In this building, a battery of $54 \mathrm{kWh}$ is installed, which may also be used for grid-balancing services.

Our energy-autonomous house has gained attention from media: Together with one of Germany's major publicly financed TV channels, I have prepared a 30 minute report about our concept, and many German newspapers and magazines have visited or invited me and publicised our insights.

The energy-autonomous house is an element of decentralised energy supply that has great potential but also faces major obstacles in its implementation. So far, the experience with zero-energy or plus-energy houses - that means, houses that produce more energy than they consume - has yielded mixed results. For example, the German Federal Ministry for Construction, Traffic and Urban Development (BMVBS) has screened and assessed 35 housing projects that are supposed to have an overall positive (both primary and final) energy balance.

According to the assessment, most of the houses have failed to meet expectations, though. The most frequent flaw is with heat pumps that are operated in 
a sub-optimal way (see also Schwoof 2013). For example, one observed house had a heat circulation system that was designed to provide the same temperature level throughout the entire house. However, the family that inhabited the house wanted to have cool bedrooms and a warm living room, and they changed the heating system accordingly, which led to a substantially higher consumption of electricity than expected.

Other flaws are related to the technologies that are deployed. BMVBS remarks that most heat pumps based on air temperatures performed worse than heat pumps based on soil temperatures or ground water.

My second idea is to favour quality over quantity. In my opinion, the German energy transformation (Energiewende) has been too focussed on quantity: producing a maximum amount of green energy, irrespective of the timing and location of feeding it into the grid. When the quantity of undifferentiated feed-in reaches a critical threshold, policies must switch to a more qualitative approach that takes the 'where' and 'when' into account. Annual energy balances that show a renewable energy surplus are often flawed similar to so-called plus-energy houses, which may have a net zero-energy balance because of a surplus of energy production in the summer - but they would still require a lot of energy from the grid during the cold and dark winter months.

Heat pumps for residential housing are an expression and symptom of the 'quantitative' approach. Their promotion is a flawed policy incentive because they tap electricity from the grid just during the months when there is very little solar power available, thus reinforcing the need for conventional backup capacity. According to my calculations, heat pumps consume four-fifths of their annual electricity total during the winter months, whereas PV panels produce four-fifths of their electricity total during the summer months. We call this phenomenon 'seasonal illusion'. A heat pump cannot be operated using a typical residential PV installation during the scarce sunshine hours that characterise northern European winters. It may lead to positive results in the overall annual energy balance, but the anti-cyclicality contradicts the objective of achieving qualitative autonomy, which means the house is energy-autonomous during almost the entire year.

\subsubsection{Business model}

By April 2016, three players had already implemented our concept.

The first business model was developed by a group of housing associations, construction companies, and private real-estate investors. Their business model is based on a 10 year contract between the company that builds and owns the house and the people who rent it. They agree on a guaranteed rent over the entire time horizon, which includes living in the flat, heat and warm water supply, electricity, and - in the near future - electric mobility. 
According to my experience, housing associations have to calculate with around $€ 380$ per square meter. For a multi-family dwelling with seven residential units, there is likely to be an additional cost of around 20 per cent, compared to a conventional building. Depending on the location, monthly rent amounts to $€ 10$ to $€ 15$ per sq. m, including the leasing of an electric vehicle.

The persons who rent the flat or the house face approximately the same costs as if they lived in a conventional house and had to purchase their electricity, heat, as well as the petrol at the fuelling station for their cars. However, they enjoy a much higher quality of living. In addition, the houses have barrier-free access. They also contain a lift for assisted living requirements and many more amenities. They also know with certainty that their all-inclusive rent will remain stable over the first 10 years.

The second business model is for energy utilities. They become a modern contractor and plan and operate all energy- and transport-related services for the multi-family building. I believe that our generation has entered the 'flat rate generation', which favours fixed payments instead of separate bills. Hence, people who rent the flat, and pay a flat rate.

This all-inclusive package substitutes for separate payments for heating requirements, electricity consumption, the leasing of a car, and the fuel at the fuelling station. Under very special circumstances - say, if collectors of amphibians have a set of energy-intensive terrariums and their consumption exceeds a certain pre-defined threshold of 'normal' usage of energy - they have to pay for the additional consumption at normal market prices, which is a payment scheme similar to contracts for internet roaming on a mobile phone.

Since the utility owns all energy-related installations, it can use them for various additional and revenue-generating functions, hence combining the management of assets and data as a service model. For example, all excess electricity and heat produced during the hot and sunny summer months can be fed into the electricity grid or sold to neighbours via a local district heating system. On days when the tenants do not need the electric vehicle that they lease, it can be rented out to other parties.

All of our projects operate with some involvement of an electric utility. In a number of projects, they just act as a service provider, in others they are the main contracting party. Utilities are changing their business model 'from selling commodities to services'.

The third business model is being pursued by banks. Two levels of involvement are attractive to them. First, they offer single-family homes. The typical target customers are people who want to have retirement plans that bring larger financial benefits than through conventional savings. In Germany, these savings are heavily taxed, so in the end, revenues after one's retirement are strikingly low. Instead, if one invests a similar amount of income into energy savings via a turnkey autarky package, these investments are not taxed when people get older. In sum, overall monetary benefits are twice as high as a conventional 


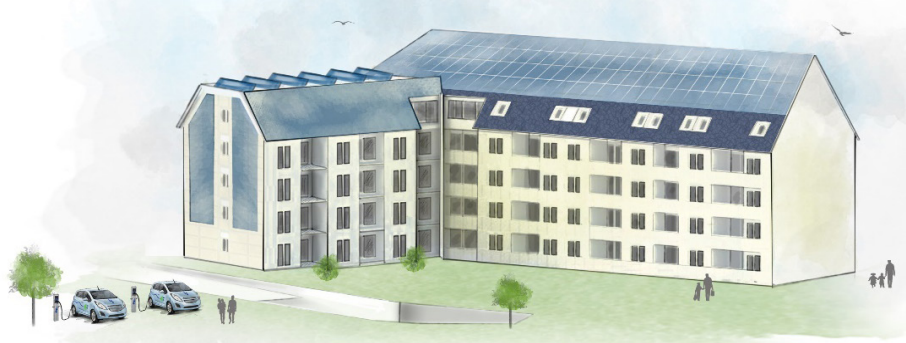

Figure 25: Planned multi-family building in Rostock.

Source: Leukefeld (2018).

retirement plan, and people use their house as a guarantee for maintaining their standard of living when they stop working.

The bank typically steps in when people intend to build a house. The bank then offers to extend the credit in order to finance the measures to enhance the energy autonomy of the house. Via these investments, the future homeowner saves money - in the case of the model house that was monitored for its performance over three consecutive years, savings of around $€ 3500$ per year for the integrated energy and mobility solution were recorded. This is a sizeable amount of money, taking continuous energy price increases into account, and extrapolating annual tax-free savings from the moment the owners move into the house until they pass away - in Germany at the age of 81 years, statistically speaking.

In April 2016, a regional bank in Thuringia started one project of this type. The bank will promote the house over the course of three years. Its intention is to demonstrate how one can achieve high-quality living after retirement.

Banks also get involved in the business model based on multi-family homes. The bank then acts both as a financier and as the landlord of these residential units. It offers a 10 year lump-sum contract for potential tenants. Simultaneously, it offers a 10 year investment opportunity to potential donors with a very attractive and secure interest rate.

This investment opportunity also has a strong ethical component because investors know exactly where their money is going, they know the location of the building, and they can identify with their investments. One project of 
that type has also been launched by a regional bank. Its director reports that demand from investors is indeed very high.

In my concept, I have abandoned principles that have been common practice in my industry. Most notably, I do not want to rely on government subsidies for the financing of my projects. If credits or grants from, say, the German Development Bank (KfW) are available for specific projects, they are of course integrated into the financing scheme.

\subsubsection{Scaling}

In April 2014, my consulting practice counted fifteen projects, of which eleven had been initiated by housing associations, two by banks, and two by energy utilities. The six-unit block offered by a bank received 50 applications from potential tenants. Instead of investing $€ 1$ million in a conventional housing block, the bank invests $€ 1.2$ million. My team analysed the demographics of the people who sent enquiries about the housing projects and found that a large number of them were elderly and retired people.

The typical process of acquiring new customers involves an initial presentation at the partner institution, for example a bank, followed by workshops with the executive board and different business units, such as credit advisors, technical staff, and so on.

My consulting practice then enters the concrete planning phase for energyrelated installations. In addition, we support the institution in its marketing efforts and in the promotion of the project by targeting customer segments which we would consider interested in the project.

It is very likely that the business model might be further refined and optimised, for example by extending the payback horizon and thereby reducing the rent and leasing costs, after a number of residential units have been in operation for a couple of years.

Another future option is to integrate commercial buildings and industrial sites into my practice's portfolio. As long as the customer is not in an energyintensive industry, such as an aluminium smelter, our concepts would work in the same way as for residential buildings. Supermarkets with standardised buildings and commercial retailers would be potential candidates. With an increasing number of projects and publicity in the media, it might only be a matter of time until a player in that field approaches us. Working with large corporate clients might pose risks for a small consulting practice like ours, though. Their corporate culture might be non-compatible with our ideas of cooperation. If the power relation is too asymmetric, for example, the client might exert pressure and force us to reduce the price of our services.

The market for retrofitting existing building stock is much larger than the market for greenfield constructions. Around a quarter of residential homes in Germany would be suitable for renovation in order to become energy-autonomous, 
according to our estimates, because these houses have large, uninterrupted rooftops facing south that could be used for solar heating and PV panels. However, the retrofitting of these houses faces two main barriers. First, investors would like to implement standardised solutions, but for a renovation, one has to take the diversity of existing buildings into account. Each renovation has to be adapted to the individual requirements of the object. Adequate insulation and modifications to the layout of the flat are basic requirements for a properly executed retrofit, which drive costs up.

The second barrier is related to rights and privileges that tenants enjoy: A renovation may increase rental costs by 100 per cent, but tenants are well-protected under German law. They would have to leave the flat and be replaced by new tenants willing to pay the required rent. However, especially if old tenants have inhabited the flat for a sufficiently long period of time, it is almost impossible to force them to leave under German law. They may successfully use the legal framework to oppose that increase in rents or the threat of getting kicked out.

With a renovation rate below 1 per cent of the existing building stock in Germany, apparently all relevant actors are failing to establish a standard solution for how to increase the rate of renovations.

According to my assessment, both commercial buildings as well as the retrofitting of existing housing stock will become relevant and attractive once the market segment with the best framework conditions - in particular, new residential units and new single-family homes - has been tapped. My consulting practice will have climbed further along the learning curve through the experiences gained from ongoing projects. For instance, one of the learnings that has already taken place concerns the configuration of the water tank, which was modified in its design in order to be more easily integrated into multi-family homes. These improvements in design could also be applied later in the configuration of commercial buildings, such as supermarkets.

\subsubsection{Market outlook and competitive environment}

Competition in the field of energy-autonomous houses is limited. A number of architectural practices and construction companies offer turnkey solutions. Pilot projects are often led by universities or start-ups based on academic research. Emphasis may not be exclusively on energy autonomy. For example, Graft Architects offers a plus-energy house that follows the cradle-to-cradle principle, which means that all materials can be fully recycled. It is built with 'healthy', organic materials, such as wood and clay. ${ }^{52}$

52 Source: Personal interview and subsequent email exchange between the authors and Lars Krückeberg (22/4/2016). 
From my experience, I believe that energy-autonomous houses can be commercially successful. If we are able to acquire even more customers in Germany, it is likely that competitors in Germany and in other countries will follow suit. Reinforced by regulation, energy-autonomous houses will become the standard rather than the exception in the newly built urban and rural environment. However, these new structures constitute typically only around 1 per cent of total housing stock in industrialised countries. The major challenge for decentralised energy will be the renovation of the 99 per cent of existing housing stock.

\subsubsection{Interviewee biography}

Prof. Timo Leukefeld studied energy engineering, worked in academia, and then founded his own company, which planned and installed solar heating systems across Germany. In 2011, he switched to consulting activities, leaving the actual implementation to other players. His current work is based on three pillars: (1) applied research and development, including the position at the TU Bergakademie Freiberg through which he holds lectures about energy-autonomous buildings,

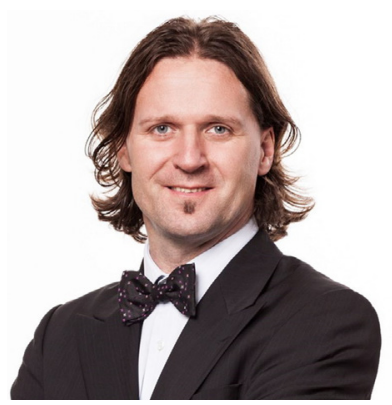
(2) the concrete planning of either new or refurbished energy-autonomous residential dwellings or commercial buildings, as well as (3) offering keynote speeches across Europe. He also serves as a strategic advisor to the federal German government and to commercial actors such as banks and housing agencies.

\subsubsection{References}

Schoof, J. (2013), Von der Schwierigkeit, ein Plusenergiehaus zu bauen, Detail, 14 August 2013. Retrieved February 11, 2019, from https://www.detail.de/ artikel/von-der-schwierigkeit-ein-plusenergiehaus-zu-bauen-10920/ 


\title{
3.5 Entelios: Demand Response - a decentralised approach to complement intermittent renewable energies
}

\author{
Interview with Oliver Stahl, founder and former CEO of Entelios, on \\ February 11, 2016
}

Entelios is one of Europe's leading energy management solution providers for decentralised energy resources in the industrial, commercial, and institutional sectors. Entelios provides Demand Response services for large commercial and industrial energy consumers. Additional clients are European energy companies in need of value-adding energy services for their B2B customers, or interested in enhancing grid and supply stability through Demand Response. As a partner, Entelios enables those companies to set up their own Demand Response programmes. Based on its leading solution suite and operational capabilities, Entelios offers automated industrial 'Demand Response As a Service.' As one of the first Demand Response aggregators and white-label Demand Response solution providers in Europe, Entelios has been building operational expertise in Demand Response since 2010 (Entelios 2018).

\subsubsection{Technology and business model}

Entelios was the first European-focussed Demand Response service provider that offered fully automated Demand Response for distributed energy resources (loads, generation units, and storage) in industrial, commercial, and institutional settings.

\section{Technology}

Together with two colleagues, I founded Entelios in 2010. I am a serial entrepreneur who worked for quite a number of years in strategy consulting. I studied electrical engineering as well as business administration, among other subjects, at the University of Mannheim. I also worked in robotics and automation and did my MBA at the Sloan School of Management at the Massachusetts Institute of Technology (MIT). While I was at MIT, in 2008, I was in search of a new business model that would fascinate me. I was given the opportunity to co-design and help organise a course called 'Energy Ventures' at MIT. For this course, we invited numerous CEOs from the energy sector and analysed where new business opportunities could emerge. Among the CEOs we invited was Tim Healy, the co-founder of the US company EnerNOC. EnerNOC has existed since 2001 and went public in 2007. During his lecture, Healy introduced us to the concept of Demand Response. In his 
business model, he pools and aggregates the flexibility of industry players to increase or reduce their electricity demand - and also their supply, in case those industrial players have distributed energy resources (many have, not only for backup purposes). By selling these modifications in demand to the grid operator, EnerNOC financially compensates the companies that participate in the Demand Response scheme.

\section{Business model}

After my return to Europe in winter 2008/09, I had numerous discussions about the idea of setting up a similar business with established players in the energy industry. When I intend to launch a new business, I do not start it by developing new software. Rather, I sign a contract with a larger industry player fairly early in the process. I present the idea and key milestones, which may be discussed with industry partners, but de facto I expect that the financial foundation of the new venture will be solid by then. For me, having customers early on is essential! If they are willing to pay, that is close to a 'proof of concept'. With this approach, a start-up does not depend just on classic bootstrapping, in particular financial support from business angels and venture capital funds.

Stadtwerke München, the municipal utility of Munich, decided fairly early on that they wanted to head in the same direction as proposed in my idea. They were already operating a 'virtual power plant' (VPP), in their case a certain number of small power-generation units (Netzersatzanlagen), which they combined into a larger, virtual generation plant. For their VPP, they used generation units that they already had, colloquially speaking, in their backyards. We presented the idea to them, in particular the idea of targeting industry and commercial players, and convinced them. They then became our first industry partner. Of course, we later received support from venture capital funds, but most important for me was that we were able to convince a large industry player of our business idea, and Stadtwerke München had already signed a contract before we even approached venture capitalists.

We then talked to the transmission grid operators and convinced them that our ideas have a solid and beneficial basis. It certainly helped us that the business model was already established in the United States and that Stadtwerke München supported us. For one year, we developed our software in collaboration with Stadtwerke München as our partner. We did the first tests together with Stadtwerke München and the transmission grid operators. We also cooperated with the Forschungsstelle für Energiewirtschaft in Munich, one of the oldest German institutes doing research on energy efficiency. They helped us to comply with all technical standards and regulations. After one year, we received the necessary certificates, accreditations, and the approval that all of our operations were in compliance with the so-called transmission code, which sets the standard for the German market. 
We sell our Demand Response product on the market for balancing energy. This market had been traditionally dominated by large generating units operated by established energy players. Then we came along and intended to do the same, but with hundreds of small entities (distributed energy assets) that we combined. They are aggregated with customised software - up to the precision of one minute - and are in compliance with the requirements of the transmission grid operators.

This took us two years. During that process, we received the first Series A of venture capital. We had a lead investor from the Netherlands, plus the HighTech Gründer Fonds - the largest early-stage investment fund in Germany and a business angel from the Netherlands. This combination gave us a financial boost, but it took two additional years to become operational because we had to overcome numerous hurdles, most of them related to the complexity of the regulatory context.

The key question for business models in the so-called Smart Grid space always is: Who pays for the products or services provided? Demand Response encompasses three types of decentralised energy assets, which provide flexibility for the electricity system - either generating units, energy-consuming devices such as lighting, or energy storage, which can be conventional galvanic elements, that is, batteries, but also other types of storage. For example, an aluminium producer may have the flexibility to control its production of aluminium blocks, which are, to some extent, stored energy.

Many contracts are needed to deal with the transactions that occur in Demand Response. Ultimately, we take flexibility in energy consumption or production from one player in the market and give it to another one. In this process, we have to negotiate contracts with our industry partners, of course, but also with operators of the high-voltage transmission grid and the lower-voltage distribution grids, as well as the administrative unit in charge of the regional balancing processes (Bilanzkreisverantwortlichen). With each of these partners, four to five contracts have to be signed individually, which adds a certain degree of complexity to the process..$^{53}$

Paulaner Brauerei, a traditional Munich brewery that belongs to the Schörghuber Corporate Group, was already active in corporate social responsibility and pursued a strategy of environmental awareness and protection. Hence, they also agreed to become our first major corporate client. We took their assets and connected them with our software. The contracts that we formulated with them later served as a reference for other clients. We took one company from an industry sector, such as Paulaner, and with that reference it was easier to approach their industry peers.

${ }^{53}$ Since the interview took place, new processes have been established that have simplified and improved the legal procedures. 
Not all industry sectors are equally attractive. The most difficult case was the chemicals industry. Processes there are already highly automated. Tiny changes in temperature can completely distort a chemical process. We went into an intense dialogue with industry players to find flexibilities. For example, a heating system based on oil or natural gas can be transformed into a bivalent process, with electricity as an alternative energy source. Excess electricity can then be absorbed by the system at short notice by switching the energy source from oil to electricity or gas to electricity. The companies became aware that just through minor modifications of a heating system they could have annual revenues of around $€ 20,000$ up to $€ 80,000$ per MW. It then took another three months to modify the facilities. In some cases, we also took over the costs to accelerate the process. With these incentives, we eventually also convinced players in the chemicals industry.

After six to seven years of actively promoting Demand Response, the industry eventually started to change its mindset. Even some of Germany's very large industrial electricity consumers are now interested in flexibility options and new business models. They want to actively engage in the energy transformation and earn money with flexibility services so that they can remain competitive with their core products on the global market.

Money to build a company is easily made available as long as there is a meaningful business model. It is not easy in the electricity sector because it is such a highly regulated market. There are many established players. For example, municipal utilities are currently in the process of redefining their strategies. Large utilities used to earn their money by selling electricity as a commodity. This has largely disappeared. Final customers are moving towards energy autarky and one day may no longer want a connection to the grid. Mediumsized companies are installing decentralised generation units in their backyards, such as small combined heat and power generation (CHP) units.

We moved into two strategic directions: On the one hand, as an independent aggregator, which is a completely new role in the market; on the other hand, we are a service provider with our software for larger utilities. We call it 'Demand Response As a Service. In the first line of business, we directly approach industrial customers and aggregate their flexibility potential. In the second, we have software and a back end that we call the Network Operation Center (NOC). Traditionally, large utilities are not used to thinking in terms of megabytes. For them, it was always 'make', sometimes 'buy' - but hardly ever 'lease'. Software as a service was not part of their mindset.

\subsubsection{Scaling and cooperations}

We have identified the top five industry sectors in Germany, including aluminium, silicon, chemicals industry, paper production, and breweries. We are looking for industries with a high degree of automation and annual electricity 
consumption of more than 10 to $20 \mathrm{GWh}$. The top management $\mathrm{CXO}$ suite has to be aligned behind the idea because support of the procurement, where electricity purchases traditionally have been located in the organisation, is not enough. We have to convince the $\mathrm{CEO}$, the operating managers of the facilities, and the CFO.

All facilities that have decentralised generation units, such as industry parks, are potential clients of ours, too. Water supply is also interesting because of the pump systems. There are hundreds of pumps, similar to gas pipelines. One has to become creative.

\section{Scaling}

We established one reference company in each relevant industry sector and then convinced their peers as well (reference selling).

We could build upon, to some extent, the established role model in the United States, but they have a different approach. Across the Atlantic, the main driver used to be the prevention of blackouts and brownouts, whereas in the German context, the driver is the integration of renewable energies and the mitigation of the volatility of those renewable energy sources.

In future energy systems, energy procurement will still have its role. Imagine a company that outsources its entire energy management. Energy Intelligent Software (EIS) is the key, and we can provide all services regarding procurement, efficiency, Demand Response, and billing end-to-end. It is not a core competence of industry players to deal with energy procurement, although many became experts in that as well.

In the energy-intensive industry, for example paper production, it makes sense to have an energy procurement unit. They sometimes even have dedicated trading floors. But for many other industries, it does not make any sense to entertain such a trading unit; they could easily outsource it. In the United States, we approach clients and suggest taking over these functions, or we provide adequate experts from our side who are either dedicated to one player or a pool of players.

Multinational companies receive hundreds of energy bills. We offer a solution that manages all of these contracts and matches the actual consumption with the billing processes. We currently have roughly 1 to 1.5 billion data entries in our IT centre every month. That is a Big Data business model. We see a company's options for flexibility on a granular level that companies would typically not be able to see themselves. We can detect patterns in the energy consumption of particular energy assets, which gives us the transparency to predict how the device will behave at a specific hour of a specific day. When thousands of those pieces of information are combined into an aggregated flexibility package, the package can be sold. But we can also do predictive maintenance because probabilities in forecasting are high. If a device behaves in a strange way, that may be a hint that there is a planned or forced maintenance event, or even a shutdown or malfunction. One could add many business models on top of Demand Response. 
Currently, our most important challenge is to grow in the area of software and IT. On a global scale, there is no real software that provides a full-fledged end-to-end solution in energy management that is similar to solutions for customer relations management or sales management. In this field, we want to position ourselves in the large enterprise segment. It is our objective to organically grow in this field.

\section{Cooperations}

Energy utilities are still sufficiently well-endowed to acquire companies and their proprietary technologies. Acquisition activities occur in cycles. Investors behave like lemmings: If a Demand Response provider is acquired, many other players in the same industry try to acquire similar companies. Our competitor in France was acquired by Schneider Electric; another competitor from Austria and Slovenia was bought by a Japanese company; a Scottish company was acquired by a Swiss player. Then large industry players such as Siemens and General Electric became aware and also wanted to become active in this field, in particular to complement their activities in the Smart Grid. We were approached by the industry. We had one offer that we considered as not being sufficient, so we employed a boutique M\&A consultancy to prepare our company for a potential takeover and invited a larger circle of potential acquirers. We realised that there are fundamental differences between the cultures of different companies. We had to ask ourselves whether we just wanted to become a business unit in a large multinational company with a workforce of 100,000 employees. It might then not be clear whether we would still be an independent business unit in one or two years.

By contrast, EnerNOC has Demand Response as their core business model, so it was a win-win. My management board gave me the freedom to decide who to partner with. Obviously, we also had many discussions about who was the 'right' partner. EnerNOC had tried to enter the Demand Response market in mainland Europe, maybe because they were too fast and somehow too 'American' in approaching, for example, traditional German utilities. However, they successfully entered the markets in the United Kingdom, Australia, New Zealand, and even South Korea. In addition, they had a very similar corporate culture and mindset, and we knew them a bit already. The story was just right.

Since the acquisition, the software aspects have become more important. When we were on our own, we did not have the entire software suite, which enables us to provide end-to-end energy management for our clients. We had software that was, in my opinion, world-class in terms of Demand Response. In other regions of the world, Demand Response is much slower and has longer lead times before it kicks in. Our software was much faster, which is why we were also attractive for EnerNOC, but we did not have all the other elements. If we sell a Demand Response product to a company, we are asked very quickly whether we can also help in other aspects of energy management. One of our 
competitors that was acquired by Schneider Electric one year before us already had the whole software suite after the acquisition. It became a difficult situation thereafter from the perspective of competitiveness.

We also had a partnership with E.ON. But when a large player like E.ON joins forces with a start-up like ourselves, it is somehow also a proof of concept that our business model and our software solution are leading edge. Depending on the pre-defined milestones to be achieved, we also received financial support from them. The collaboration was handled mainly by E.ON's sales unit, but sales are driven by the personal objectives of each key account manager to sell more power and gas, and Demand Response is just a small side product that only makes a marginal contribution to their target agreements. It takes time to establish that process and to formulate the templates for the contracts often more time than a start-up actually has. We had to see success at a faster pace. It helped us to learn how to make our product more complete.

Now we have a sales unit for the utilities, and we have key account managers for individual industries, such as the paper industry. I am looking for sales managers who have access to CXO suites and a track record in high-level sales, someone with expertise in electric devices and a successful sales profile.

Energy utilities are scared of what could happen if Entelios ceases to exist. For instance, they would have liked to acquire Entelios shares, but I wanted us to be able to provide services also to their competitors in the future. Nonetheless, we had to cooperate closely with larger utilities. In one instance, we were very disappointed when a player then tried to copy our product. But we had long-term cooperations with faithful players such as Dong from Denmark, Verbund from Austria, BKW from Switzerland, and the Stadtwerke München. They realised that they would not be able to manage the energy transformation by owning all the intellectual property and software, and they made efforts to find partners with whom they could jointly develop new products and services. Together, we have to build an ecosystem and a peer-to-peer landscape.

It is unclear where Entelios fits into the organisational structure of a traditional utility: The sales units have contact with the end-customers, but there are also the generation unit, the innovation department, and the trading unit that would potentially fit. Utilities did not know where to position us because we provide a product for the market for balancing energy and managing the consumption as well as the production of energy assets, hence we should belong to the generation unit. But we also do trading, and we directly approach the final customers in the industry and aggregate their flexibilities in energy consumption and production.

Fairly early in the process it became clear that we should be linked to the sales department if we wanted to be successful. For the sales personnel of a utility, who have been selling energy over decades, it is difficult to sell the opposite - a reduction in energy, which is a 'totally different animal'. In the beginning, only very few sales managers were willing and demonstrated the 'mental flexibility' to focus on the new concept of Demand Response. 
Interestingly, large utilities launched spinoffs, new ventures that were 100 per cent owned, of course, by the utilities, with some internal but also external staff that were targeted directly for developing new business models for the energy transformation. I believe this is the right way. Those who have always worked in the old energy world have had a harder time imagining that their old world may one day completely disappear. Few understood that customers had to be approached in a completely new way.

For example, an industrial client may want to launch a new product. All the equipment that concerns building efficiency, energy provision, and all the technical details may no longer belong to its core competencies and strategy. When we started, municipal utilities did not have the idea of building and/or providing services, for example for a combined heat and power (CHP) unit and leasing it to their industrial clients. In contrast, where would a municipal utility earn its money with an increasing number of residential customers who do not need a grid connection, because they have become energy self-sufficient? Utilities need to think of new business models. For example, municipal utilities could build new housing units and equip them with all energy-related technology, including PV panels, heat pumps, and all other elements of building efficiency. That utility may then no longer charge for electricity or gas, but rather a fixed, all-inclusive rent for the individual flats or housing units. A frontrunner for those novel concepts is the Freiberg Institut (www.freiberg-institut.de/), under the leadership of Dr Timo Leukefeld.

\subsubsection{Market outlook and competitive environment}

Imagine walking into an industry player's facilities and telling the management: From now on, I want to steer and control your assets. Then all sorts of resistance emerges. For example, the people in charge claim that their facilities are already highly energy-efficient. Companies also raised questions about the reliability of our operations, what would happen if we damaged their assets, and how much we really earned with our business model.

It is a paradigm shift. For more than 100 years, supply just matched demand, but now supply has become increasingly volatile with the deployment of renewable energies. When the wind blows at $4 \mathrm{am}$, residential customers are still asleep and industrial processes have not yet commenced. Today, the wind rotors have to be shut down, but in the future, we will explore opportunities to temporarily store the power. For example, at $4 \mathrm{am}$, all air pressure compressors (Luftdruckkompressoren) in Germany could be filled with air. Compressed air just acts as an intelligent storage device, similar to a block of aluminium or silicon.

The emerging business of aggregators managing flexibility and the underlying energy assets are typically active in biomass with small, decentralised 
generation units, but they are operating in a completely different business model. We have observed large revenues but small profit margins. There are indeed already three larger aggregators that are active in load management and storage. An upsell is difficult for these assets. Selling additional services to a rural community with biomass assets is difficult. We decided that we would not head into this direction, but instead focus on industry and commercial businesses.

In our nascent industry, competition is very healthy because it gives the impression to potential clients that there is an attractive market, and in the end the overall size of the market increases.

In the United States, establishing a new business model takes less time than in Europe. When brownouts were looming, people literally called large consumers via telephone to shut down parts of their assets. They were much more pragmatic than here in Germany. Demand Response in the United States works via email, text messaging, and call centres, as opposed to our highly automated system in Europe. Second, politicians very quickly embraced the concept, and the US Congress ratified a Demand Response action plan, which led to a modification of the sector's regulations and legislation. With this move, the role of the market aggregator became legally accepted. Third, large associations were founded, and lobbying activities were more pronounced.

In Germany, we have to be grateful to some extent to the Green Party for promoting renewable energies. But we could also blame them for not having thought about the wider system, for example adequate storage solutions, transmission lines running north to south, and the reinforcement of the grids. It was a mono-dimensional approach, and now we have a transformation (Energiewende) with huge flaws and ineffective markets. Above all, the self-imposed $\mathrm{CO} 2$ reduction targets cannot be achieved.

When we talk with associations about municipal utilities, they recognise the value of our business model, but they do not want to actively push it because they want to allow their subsidiaries to develop their own technologies and become market-ready.

In Brussels, we co-founded the Smart Energy Demand Coalition (SEDC, which is now Smart Energy Europe, www.smarten.eu), together with other innovative energy players and stakeholders. The former EU commissioner for energy, Günter Oettinger, quickly grasped the benefits of Demand Response. Not long thereafter, Demand Response was part of the energy-efficiency guidelines of the European Commission. In Germany, back then in 2014/2015, this had not yet been implemented into national regulations. This was probably because Germany had so many other questions to deal with on a national level, but it is clear that a further expansion of renewable energies - combined with a shutdown of all nuclear assets by 2022 and all coal plants by 2030 - without Demand Response will face challenges in terms of a stable supply situation. If no wind or sun are available, we have to have a backup option for the domestic 
baseload of around $80 \mathrm{GW}$. Alternatively, we would have to install adequate storage capacity - but where should this come from?

Renewable energies cannot yet completely substitute for traditional power plants. In particular, we are lacking the transmission lines to transport electricity from the north to the south, but more importantly, we do not have sufficient storage capacity. One could imagine the gas grid with power-to-gas, or Demand Response, or stationary grid-scale batteries, or even batteries for residential households, as it is currently evolving in the United States. We need all these options, but we should have started much earlier, developed a comprehensive plan, thought about these options, and pursued R\&D activities in these fields. We should have been focussing on these topics since the late 1990s.

In the United States, large electric utilities claimed that Demand Response is a retail-oriented business model, but it operates with wholesale prices. The Federal Energy Regulatory Commission (FERC) allowed Demand Response to participate in wholesale markets, but some states claimed that this was beyond the FERC's authority. But the US Supreme Court decided in favour of the FERC's order. In January 2016, the Supreme Court of the United States announced that it sided with EnerNOC and the FERC in the case of EPSA $v$ FERC. This gave EnerNOC a boost of confidence, which was reflected in its stock prices: It fell to US $\$ 4$ and then rose again by 70 per cent on the day of the Court decision. If the Court had decided against us, a large portion of our portfolio would not have been able to participate in the capacity markets, and a large part of our cash flow would have been at risk.

\subsubsection{Interviewee biography}

Oliver Stahl was founder and CEO of Entelios $A G$ (www.entelios.com), and later, after the acquisition of EnerNOC, Managing Director Europe for EnerNOC. He still serves as Senior Executive Advisor to the company. Since April 2017, he has been CEO and co-founder of Robotise (www.robotise.eu), a start-up whose mission is to introduce service robots into people's everyday lives.

Oliver is a serial entrepreneur and was also a management consultant in a global consult-

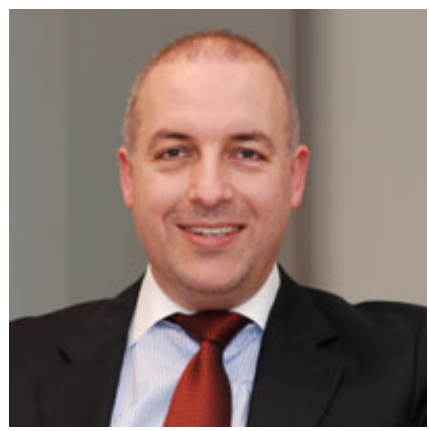
ing firm for several years. He is co-founder and a board member at SEDC, Smart Energy Europe (www.smarten.eu), a European industry association with more than 50 member companies with a focus on Demand Response, demand-side management, and energy efficiency. 
Oliver started his career as an electrical engineer in the area of industrial automation and robotics. He studied business administration and educational science at the University of Mannheim, then at Loyola University and Northwestern University in Chicago. In 2008 he became a Sloan Fellow and received an MBA degree from MIT Sloan School of Management.

\subsubsection{References}

Entelios. (2018), Consumption follows generation, demand follows supply. Retrieved February 10, 2018, from http://entelios.com/entelios/ 


\title{
3.6 SOLshare: decentralised energy supply - complementary or antagonistic to rural electrification
}

\author{
Interview with Sebastian Groh, Co-founder of SOLshare, on January 9, 2017
}

SOLshare is a Bangladeshi Ltd. ICT company founded in 2015 that has created a revolutionary new approach to bring affordable solar electricity to everyone in Bangladesh and beyond through its peer-to-peer solar energy trading platforms. SOLshare is at the brink of creating the next generation of electricity grids. The social enterprise pioneers a micro-energy transition model 3.0 interconnecting solar home systems, monetising (excess) solar energy along the value chain in real time with mobile money, and empowering communities to earn a direct income from the sun (SOLshare 2018).

\subsubsection{Technology and business model}

In 2009 I started working at MicroEnergy International, a Berlin-based consultancy specialised in decentralised energy services. We first looked at sharing electricity from an academic perspective. I did my dissertation on the topic of innovation and energy service supply along certain development processes as an economist, and a colleague of mine made contributions from an engineering point of view. We basically found two things. First, when a solar home system is designed, there is a trade-off between the rainy season and dry season. This means that either the battery has sufficient capacity to capture all of the power generated by the panel (but then it will never be fully charged during the rainy season), or a smaller battery is provided, albeit with the disadvantage of it never reaching full autonomy during the rainy season. After two days of constant rain, the system will go offline. In Bangladesh, we would like to have at least three days of full autonomy. We had to settle on somewhere in the middle. That also implies that around 30 per cent of what the panel could produce over the year cannot be stored by the battery and goes unused, which is $600,000 \mathrm{kWh}$ daily! That is the equivalent of driving a Tesla Model S 68 times around the globe every day. There is a massive potential available across almost five million solar home systems just in Bangladesh.

Our second observation was that there were already lots of people sharing their electricity, for example by going to a neighbour and asking them to charge a phone, or there was someone who did this on a commercial basis and took a certain fee for that. But we also saw people connecting their households with cables to their neighbours and paying per hour of light bulb use. They had to monitor this at all times, though. Translating these fees into kilowatt hours opened our eyes: from US $\$ 3.50$ up to US\$10 per $\mathrm{kWh}$ is what 
we economists call the energy-poverty penalty, and what we entrepreneurs call a massive market opportunity. Combining these two insights creates an opportunity in which everybody can win. People are willing to share and pay for power, and there is excess electricity available. Plus, there are still many households that cannot afford a solar home system, despite the micro-credit schemes. However, the sharing scheme can be designed to be inclusive enough to make it affordable for them as well, while turning other prosumers into local energy entrepreneurs.

In Bangladesh, there is an extremely high density of these solar home systems. Our idea was to connect these systems and, based on the connections, to increase overall capacity through synergy effects. At the same time, in order to achieve a certain level of diversification, we would tap into the unused 30 per cent potential. We started from this idea and called it 'swarm' electrification, in which the swarm is more powerful than the individual unit and we would have peer-to-peer communication. Each system speaks to the next system. If one system drops out, nothing happens - a fairly resilient model. In contrast to a conventional mini-grid, which has a determined system size, our model can also grow organically.

If we interconnect solar home systems and incrementally add more generation and storage sources, we will have a much better business case because our capital expenditure (CAPEX) is limited to the cabling from house to house, as well as to a bi-directional metre, which we call the SOLbox. It essentially works as a net metre. Whenever a household is a net consumer, its balance decrease - not in kilowatt hours, but in Taka, the Bangladeshi currency. Whenever a household is a net producer, the balance increases. The balance is directly mirrored on the mobile phone in a mobile money wallet. Then that money can be used in real time for payments of all sorts, not just energy. That is the biggest value proposition for our customers.

\section{Technology}

We develop the SOLbox in Bangladesh. Then we have a couple of suppliers in China from whom we order the printed PCBs (circuit boards). We produce the case in Dhaka and also do the assembling and testing there. Because of the evolution of the sector over the last 15 years, the local workforce is well-prepared.

The cabling and the WiFi tower should be covered by the membership fees. The partner organisations (POs) can get much better rates than us to purchase the cables due to their good relationships with the suppliers. We tell them when something is needed, then they buy it themselves and recover their costs, plus a margin via their subscription fees.

From the perspective of maintenance, our system is slightly more complicated than the average system. We have developed a training-of-the-trainer concept: We are training the regional managers of the POs to then train 


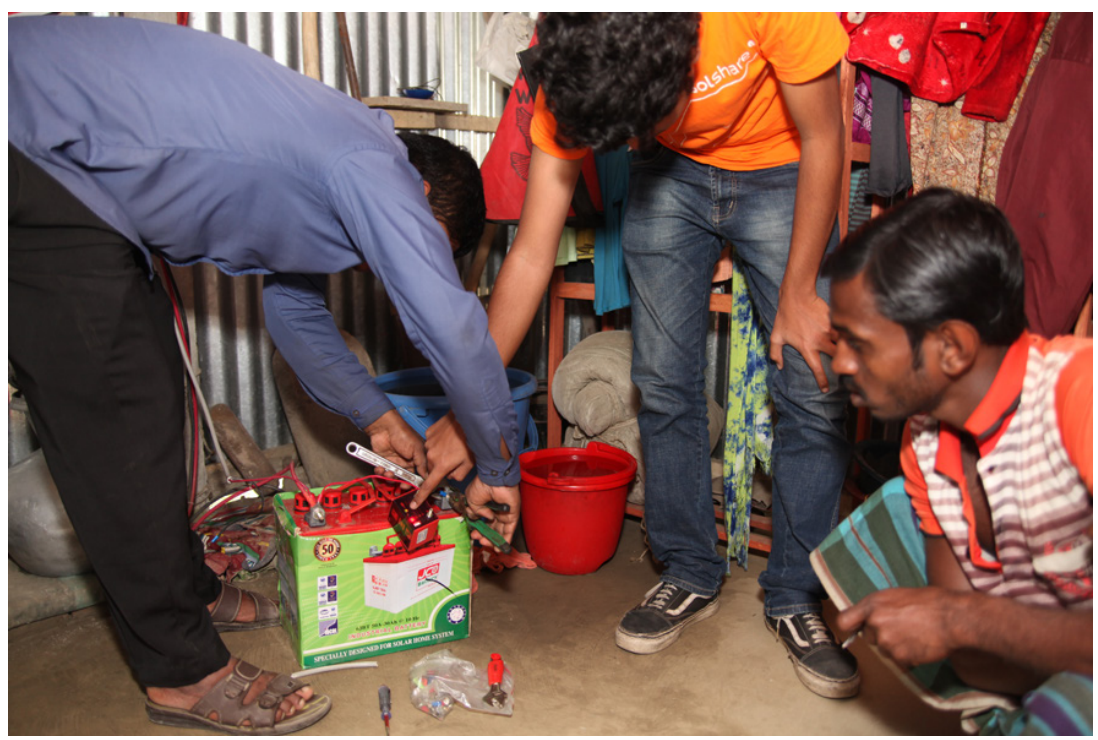

Figure 26: SOLshare's field operations team providing technical support. Source: SOLshare (2017).

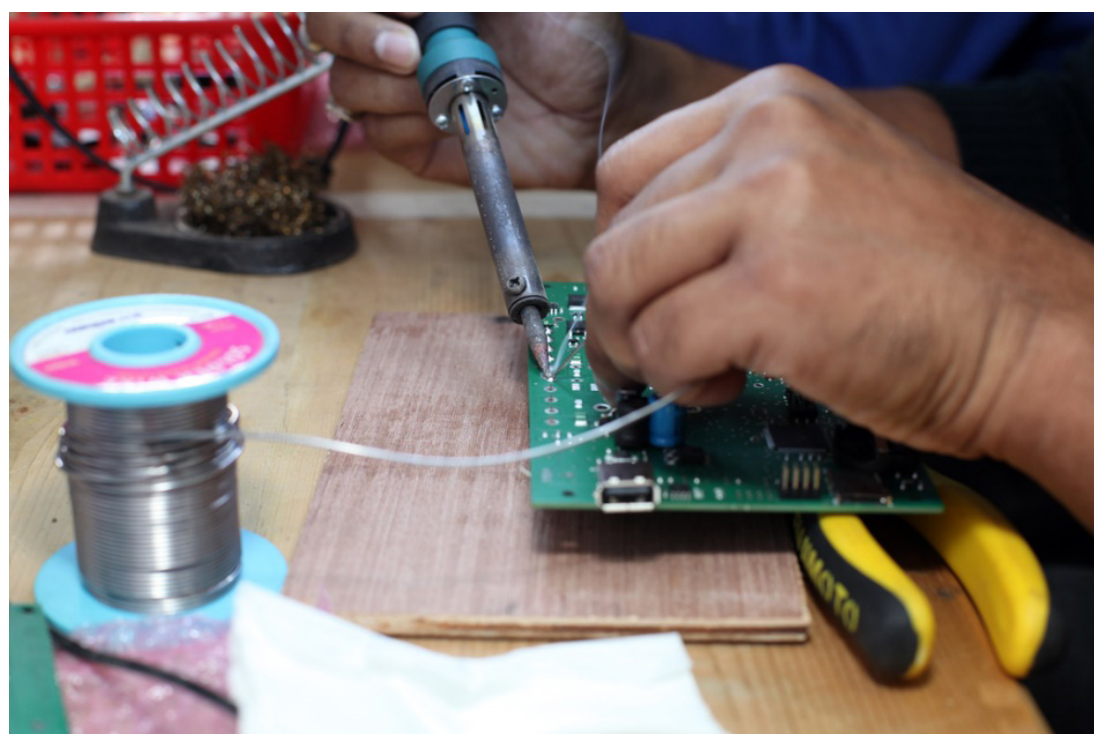

Figure 27: Production facilities in Dhaka.

Source: SOLshare (2017). 
their staff - also in terms of marketing. They recommend that people get a mobile wallet if they do not already have one in order to avoid having cash in the field.

\section{Business model}

The Bangladeshi solar home system sector really started in 2002/2003 with the launch of the Infrastructure Development Company Limited (IDCOL), the governing body of the programme, which is under the Bangladeshi Ministry of Finance. Since then, around US\$750 million of development finance money has gone into the sector, all channelled through the IDCOL to bolster the ecosystem of solar home supply. Up until 2016, more than 4 million solar home systems had been installed.

We basically run a mixed business model that has B2B and B2C elements. Our first customers were the implementers of solar home systems. We piggyback on the existing infrastructure and cooperate with more than 50 partner organisations of the IDCOL, which provide both technology and financial credit to the customers in a one-hand model. Over the last 15 years, the World Bank and other institutions have given loans at very low interest rates to the IDCOL, which passes it on to the POs at a slightly higher interest rate. The POs then provide two- to three-year loan contracts to the end-users at an interest rate of 8 to 12 per cent.

Our SOLbox is an additional component of their solar home systems. We sell it to the POs, for example Grameen Shakti or Bright Green Energy Foundation, among others - the former being the biggest PO with more than 1.7 million systems currently installed. The PO then integrates it into their solar home systems. We also retrofit (upgrade) existing systems, but always in cooperation with a PO.

Our revenue stream is threefold. We first have a margin on the SOLbox, which we sell to the POs. Secondly, similar to an Uber business model, we take a fee for every transaction. When neighbour A transfers money to neighbour $\mathrm{B}$, there is a spread, and this money goes into our mobile wallet. This is the B2C component of our business model. However, we share this fee with the POs - also to give them an incentive to keep the grid running and encourage further expansion.

The third revenue stream is a fee for managing the grid, which the POs transfer to us. They can decide by themselves how to charge the customers for this service. As we have WiFi towers in the villages, our SOLboxes communicate with the WiFi towers. We did not want to integrate a GSM chip into each box, which would have turned out to be too expensive. The WiFi tower is the single point of communication to us. With this technology, we can monitor at all times how much electricity is being generated as well as how much is being consumed and traded. With this information, we can determine which appliances are being used and which other appliances could be used with more 


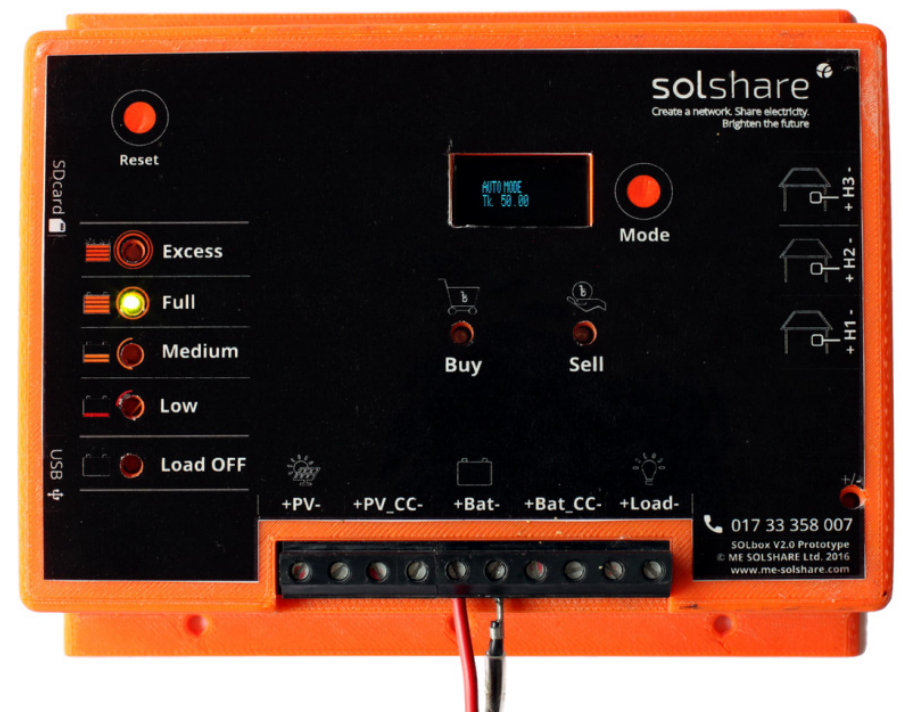

Figure 28: The SOLbox.

Source: SOLshare (2017).

generation capacity or more storage capacity. These diagnostics and analytics are sold as a service package to the partner organisations.

Typically in mini-grids, there is a connection or subscription fee, which is either one-off or recurrent. Together with the POs, we are still looking for the optimal business case. Still, a lot of people need to be convinced that they can earn money with their solar home systems. The general understanding is that it is purely a consumptive good, but suddenly we have turned it into a productive good. Second, it is a connectivity good that we are pitching - together with the POs - to the end-users.

If a residential customer buys a new system, it costs about US\$360 over the period of a 36 month loan. That is US\$10 per month (ignoring interest to make it simple). The SOLbox is sold for US\$24 to the PO. The PO then puts a 20 to 30 per cent margin on top. We calculate a recommended end-user price of around US\$30, which is less than a dollar per month of additional expenses. If customers sell $1 \mathrm{kWh}$ for US\$2 each month, they make a net profit from month one onwards. Obviously, it cannot be guaranteed that they will actually sell a kilowatt hour each month. Maybe when they want to sell, nobody will want to buy. To take that into account, we put a buffer system into the village - like a micro-utility, where the electricity is buffered. We then connected a water pump to the buffer system, which is a nice load because the water pumping can take place during the day and not so much in the evenings. The electricity 
can also be used for alternative devices such as corn shellers or rice cutters. Recently, we launched our first pitstop solar rickshaw charging stations, where rickshaw drivers can charge their vehicles during their lunch or tea breaks. In the evening this pays off, as they can ride their rickshaws an extra hour before they have to make their way to the closest national grid point.

In the traditional ABC mini-grid model (anchor, businesses, community) everything is designed for a specific anchor, usually an outside investment, which eventually takes out the return at some point. By contrast, in our system the grid is designed for the community. The community grows its own capacity to power anchors, and the returns stay within the community as well. So one could refer to it as a reverse ABC model. An average household in Bangladesh earns between $€ 50$ and $€ 100$ per month, the 'rich poor' in the villages, plus around $€ 1.50$ from selling electricity. But we are targeting microentrepreneurs: Knowing that one can earn money with our installations, local residents install extra panels and make additional profits. The price per panel is very cheap, meaning that one can make a lot more money. As a reference point, a kilo of rice costs about $€ 0.50$. With three to four kilograms of rice, one can get quite far.

We also have a second product. It is our retrofitting model from post-paid to pre-paid, which we call the SOLcontrol. There is a payment crisis in Bangladesh, which means the repayments on loans for the solar home systems have significantly plummeted; repayment rates have dropped from up to 95 per cent

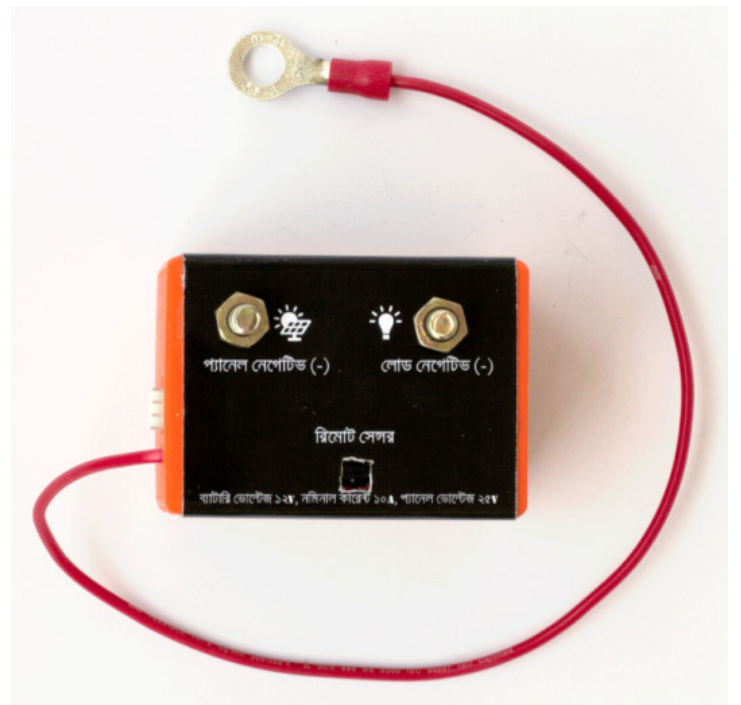

Figure 29: The SOLcontrol.

Source: SOLshare (2017). 
down to 30 per cent. We are targeting this with two actions. In existing systems, we can easily retrofit them from post-paid to pre-paid to make them pay-asyou-go. We are thereby trying to help the POs to keep their good customers so that they do not - through a domino effect - become bad customers, and to help them turn some bad customers into good customers. Enforcement is also better if we can electronically lock the system rather than go into the village and uninstall the systems, which is in most cases not happening anyway.

The SOLcontrol is a good learning case for supplying 150 households in the first month, and 5000 in the following months. We will grow with this experience, because, together with the SOLbox, the business model will become more complex. We are diversifying our business model every day and really have to simplify and focus. We have a lot of options in terms of pricing, but we have not found the optimal model yet. Maybe we will scale up with a different pricing model.

\subsubsection{History and organisation}

SOLshare, located in Dhaka, Bangladesh, is a spinoff of MicroEnergy International, a Berlin-based consultancy specialised in decentralised energy services. The foundation was set through the Stanford Ignite Program in 2013, when I pitched the idea of swarm electrification for the first time, and the first business plan for SOLshare was developed. I was later joined by Hannes Kirchhoff, our CTO, and Daniel Ciganovich, our Director of Business Development, my two co-founders. In September 2015 SOLshare managed to install the world's first cyber-physical solar peer-to-peer sharing grid in a remote Bangladeshi village.

\subsubsection{Scaling}

After having set up our first 10 grids throughout the country, we recently received the US\$1 million UN DESA Powering the Future We Want prize in collaboration with Grameen Shakti. With the help of this prize, we are determined to set the foundation to interconnect the maximum amount of Grameen Shakti's 1.7 million solar home systems in the upcoming years and also expand beyond the borders of Bangladesh, possibly even to Europe.

A major challenge here in Bangladesh is an aggressive approach for grid extension, indiscriminate of the associated costs. Electrification costs highly depend on the distance of how far the grid needs to expand to the next household and the associated load pattern. When we start interconnecting houses with cables, the closest house to the national grid could be the point of common coupling, that is, the one node that connects to the grid. In our $R \& D$, we have built a Gridbox, which could potentially serve this purpose. The Gridbox is something like a Smart Metre or a bigger SOLbox, but with additional 
functionalities, such as converting the electricity from AC to DC and lowering the voltage. In addition, it could control the entire network connected to it. The government would then only have to connect to the point of common coupling. What is behind the cable infrastructure has already been developed by us. The only problem is that the tariffs of the SOLshare grid are significantly higher than the subsidised tariffs of the national grid. We have to do a comparative study on the costs of electrifying additional houses versus connecting just the point of common coupling and then paying the gap between the two tariffs to the connected households. That certainly depends on the distance, but it may be a commercially viable alternative. In Bangladesh, the range of DC appliances are being expanded every year. Light bulbs, TVs, fans, and now fridges are available in high-efficiency direct current. Water pumps, rice cutters, and corn shellers can all run on DC. What can the national grid offer these people that is better than if we managed to fully electrify them on DC and on solar home systems?

If we connected households with the point of common coupling, the national grid company would have to compensate us for building the local grid infrastructure. But this money does not have to come to us. It can go directly to the households and could even be a direct cash transfer.

We do not need the national grid. As our network can grow dynamically, we can incrementally add more capacity if we observe that there is more demand. We can then approach the households and suggest adding capacity, with which they can earn a lot of money. The entrepreneurial drive and financial incentive provided by our platform should be sufficiently strong to let the grid grow organically. From the feed-in perspective, the grid could be quite attractive, though. At times, it could be used as a buffer, and when it encounters problems, one could switch off all the connected households with just one node. It often occurs that when the grid is down and then starts running again, it immediately crashes because all households still have their switches on and the whole load affects the grid's stability. If the grid is down and then is switched on again, we can manage that gradually and thereby increase system stability.

The biggest challenge is getting aligned with the utilities and the government. The medium-term vision may depend on the aggressive rollout of the national grid. We plan our grid by giving people the financial incentive to make their local grid self-sufficient.

We can put our infrastructure on any system, including the low-cost modules of Chinese PV manufacturers. The appliances for the solar home systems are available everywhere in Bangladesh. Of course, if we build it on a poor-quality system, the question is: How long will it last? It is half the cost of a system provided by the IDCOL. It is available commercially and quick to install. One would not get any warranty. A recent World Resources Institute study showed that prices in Bangladesh are already very low compared to other countries, especially in East Africa, and the battery comes with a five-year warranty. 


\subsubsection{International expansion}

Since winning a couple of awards with our concept in 2016 and 2017, we have been receiving numerous requests from all over the world. In principle, we are interested - but not right now. First, we have to carve out a solid business model here in Bangladesh: For the SOLcontrol it is done, but for the SOLbox it has not yet fully proven itself. Once we have that, we can start expanding to other countries. Of course, we have to take other factors such as population density into account. Would it then also be a B2B model, or rather B2C? Is there already a network of solar home systems that we can piggyback on, or do we need to start in a greenfield environment?

\section{Cooperations and new technology developments}

Our financial partner for the money wallet is bKash - the largest mobile money provider in the world, among others - which has recently surpassed M-Kopa in transaction volumes. Mobile money means that customers have their mobile money on their phones. bKash agents are present all across the country and have small stores where customers can charge their phones and make payments. We set up one wallet for these people, which we call the 'energy wallet'. Some people also call our system 'the energy bank'. One time a rural woman approached us and said that she really liked our system, but what she was missing was knowing how much money (!) was in her battery. That is a typical asset calculation approach. It is amazing to see how people in remote areas of Bangladesh have now started to realise that electricity now equals money for them. In urban Dhaka, we are far from that.

Recently, we have started to look into blockchain technology and the degree to which we could reap the benefits. We are collaborating with freeelio and the German Blockchain Association to develop a tokenisation model. We are setting up a programme label: Energy Efficiency in Germany for Energy Access in Bangladesh, where utilities or private consumers can decide to transfer their money from electricity savings directly onto the metre of the Smart Metres in the SOLgrids in Bangladesh. This will become the most transparent, efficient, and safe way to make a conditional cash transfer to a developing country.

\subsubsection{Market outlook and competitive environment}

In Bangladesh, the rollout of the national grid was very aggressive. We did a study of 350 households in rural areas: Half of them were connected to the national grid and the other half were close by, but without access to the grid. The result was that the solar home system provided a significantly better electricity service than the national grid, based on the multi-peer framework for measuring energy access, as developed by the World Bank. Quality of access here is measured against multiple attributes such as capacity, affordability, 
safety, reliability, and so forth. The national grid performed so poorly because of its reliability. The key indicator was the number of hours of available electricity between $6 \mathrm{pm}$ and $10 \mathrm{pm}$. During these hours, the national grid often suffered from load-shedding in the rural areas investigated. What we observed on the ground is that if politicians promise households that they will be connected to the grid very soon, it is close to impossible to convince them to consider any alternative form of electricity supply. By contrast, with households that are already connected to the national grid and have had their experiences with it, we have a good chance because they know they need a backup - or even a complementary - system.

\subsubsection{Interviewee biography}

Dr Sebastian Groh is a 2013 Stanford Ignite Fellow from the Stanford Graduate School of Business (USA) and holds a PhD from Aalborg University (Denmark) and the Postgraduate School Microenergy Systems at the Technische Universität Berlin, where he wrote his thesis on the role of energy in development processes, energy poverty, and technical innovations. He has published a book and multiple journal articles on the topic of decentralised electrification in the

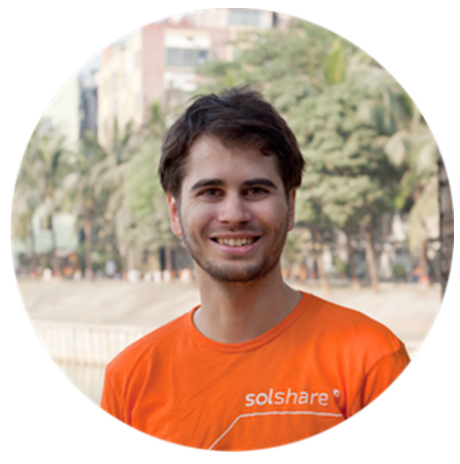
Global South. Since 2014, Dr Groh has been working as the CEO and co-founder of SOLshare Ltd. and is an assistant professor at the Business School of North South University in Dhaka (Bangladesh).

On behalf of SOLshare, he received the Intersolar Award for Outstanding Solar Businesses, the UN Momentum for Change Award, both in 2016, as well as the 2017 Start-Up Energy Transition Award from the German Energy Agency (DENA) and the 2017 UN DESA Powering the Future We Want US\$1 million Energy Grant, along with Grameen Shakti from Bangladesh. Dr Groh was further selected for the SE100 2017, a list of the top 100 Social Enablers around the world.

\subsubsection{References}

SOLshare. (2018), Create a network. Share electricity. Brighten the future. Retrieved February 10, 2018, from https://www.me-solshare.com/ 


\subsection{Mobisol: developing a pioneering business model for off- grid energy in East Africa by starting with the users}

\section{Author: Klara Lindner, Mobisol GmbH}

'A typical household in Bangladesh using kerosene lamps and rechargeable car batteries for lighting, TV, and other applications spends an astonishing $€ 1.50$ per $\mathrm{kWh}$ - compared to the subsidised price for grid electricity of only $€ 0.03$ per $\mathrm{kWh}$ in Bangladesh and the slightly higher price of more than $€ 0.20$ in Germany. ${ }^{54}$

\subsubsection{Context and origin of the idea}

Although the electricity plug has long become indispensable in our daily lives, a quarter of the world still lives in areas without any form of modern energy provision - with most of those affected residing in sub-Saharan Africa (620 million). Countries such as Tanzania have electrification rates of 24 per cent. In rural areas, this number drops to less than 10 per cent. With the majority of the population living in village communities, this leaves 36 million people living off-grid in Tanzania.

In these unelectrified areas, only a few low-power-consuming activities are possible, and they are accessible only by people who own a diesel generator (and can handle its noise, fumes, and maintenance needs). In countries close to the equator, the sun sets at $6 \mathrm{pm}$, meaning it is completely dark at $6: 05 \mathrm{pm}$. People who want to finish things thereafter, be it work, household chores, or homework, need to rely on candles, kerosene, or battery-run torches.

The majority of people living in these off-grid regions belong to the 'base of the economic pyramid' and have limited disposable income. In addition, the weak infrastructure in these areas - most of them are difficult to reach - makes this part of the population unattractive as potential customers for most companies around the world.

This is where Thomas Gottschalk comes into play. Driving around the globe with the 'Solar Taxi' in 2009, he noticed two things in the developing world. First, these people's realities are far from the stereotypes we are commonly confronted with in Europe: People rarely live from subsistence farming only - there are flourishing informal markets everywhere, especially in those areas that have some kind of grid connection, thus allowing for diversified

\footnotetext{
${ }^{54}$ Source: https://www.microfinancegateway.org/sites/default/files/mfg-en-paperfact-sheet-the-potential-of-linking-microfinance-energy-supply-mar-2010.pdf.
} 
economic activities. Second, the mobile networks in most rural areas were better than in the village of Gottschalk's grandmother back in Germany. And every person he met had a mobile phone, which they used not only for communication, but - in more and more countries - also for transferring money from person to person. Apart from that, as he was trained as an energy engineer, he knew of the price decreases in photovoltaic (PV) systems and how these, with their modular set-ups, are applicable in hard-to-reach areas. He sought out a handful of other like-minded people who had come to very similar conclusions. Together, we started to turn these three insights into a business: Mobisol.

\subsubsection{Phase 1 (pilot phase): what do we provide then, really?}

The basic concept was thought up quickly: Sell self-sufficient photovoltaic systems to individual households in off-grid areas, let customers pay with mobile money over time, and remotely turn the systems on or off through a modem with a SIM card that is placed in each system. But what we did not know was: What is the concrete value proposition, how do we reach our customers, and what does the detailed revenue model look like?

We found an angel investor who was fond enough of the idea to make a small grant for us to get started. Rather than wasting time on a 50 page investor deck, we turned the concept into a tangible prototype. At this point, it was basically a light bulb and a solar panel connected to a microchip with an embedded SIM card. Sized to fit in a suitcase, we could take it anywhere we wanted and easily demonstrate the concept to potential partners: Give them the phone number of the system, and by sending an SMS with the text '1', they would turn on the light and the penny dropped.

We first used this to get in touch with mobile network operators that were offering mobile money in off-grid areas and to create a service agreement with them. By that time, only four countries worldwide - Tanzania, Kenya, Ghana, and India - had implemented M-Pesa, the mobile money platform that radically eases the collection of small payments in rural areas. India was not included because we did not know anyone there, and the time zone difference would have made things even harder. So in May 2011, a small team of three set out on a field trip to Tanzania, Kenya, and Ghana with two aims: first, find a local, like-minded organisation to work with in rural areas; second, and most important, go out and talk to future customers, understand the way they live, the way they earn a living, and the role that energy plays in their lives.

We hired a car, found a translator, and started the engine. For the next four weeks, we would meet local renewable associations, drink tea in Tanzanian living rooms, attend weddings in Ghana, and hold discussions with the elders 


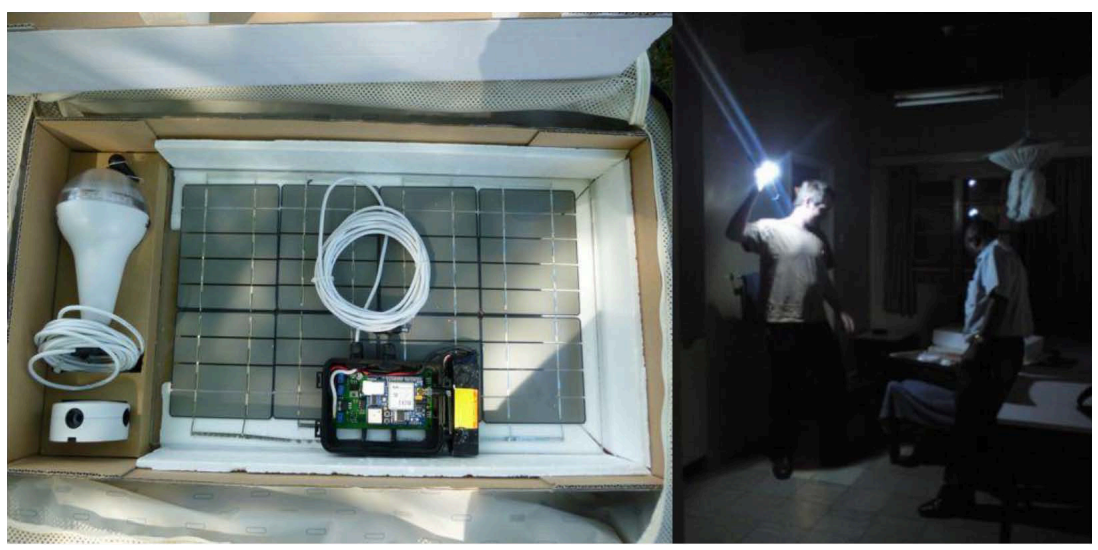

Figure 30: The suitcase-sized prototype and its demonstration to a potential partner.

Source: Mobisol/Lindner (2017).

of the Maasai tribes under the community tree. We quickly realised that the awareness about PV solar was high, but also that bad quality materials had ruined its reputation. People valued bright lights, but kerosene lamps were still 'good enough'. Getting access to 'real electricity' that powered stereos and TVs was what people really wanted. If there was something that they really wanted, they would find a way to pay for it. We realised that their ability to pay was much more volatile than we thought.

Based on this field research, we knew what the product of the pilot phase should look like: complete all-in-one kits big enough for real appliances (to fulfil willingness to pay), plus credit financed over three years (to ensure ability to pay). We wanted to include after-sales (to ensure long life), and favoured ownership rather than rental solutions (to make sure people take good care of the product).

So we designed a first offer that we could test with real customers: We went for three different PV all-in-one systems (60 Wp, $120 \mathrm{Wp}, 200 \mathrm{Wp}$ ) and a 36 month credit and technical services agreement.

For this, a second hardware prototype was developed, now fully functional. We could remotely turn the PV system on and off based on incoming mobile money payments, and we could gather performance and usage data in real time to foresee maintenance activities through the modem inside the system. We used material from the Tanzanian DIY store for the casing, which was not only cheap, but ugly enough so that our pilot phase customers would understand that this really was only a first shot and that we would warmly appreciate their feedback. 


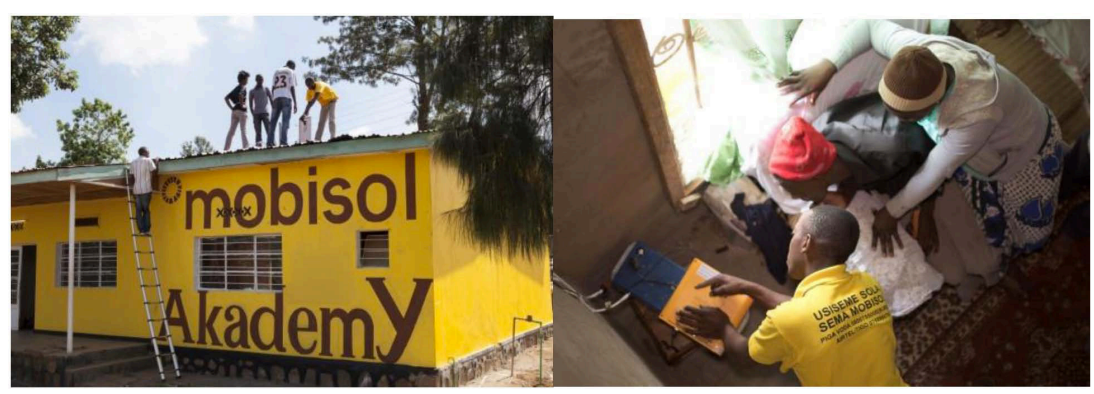

Figure 31: The Mobisol Akademie in Arusha, Tanzania, and a trained installation technician in action.

Source: Mobisol/Lindner (2017).

With our local partner organisation, we created a concept for awarenesscreation, marketing, and sales within a few months and started our pilot phase with 100 paying customers in October 2011 close to Arusha, Tanzania.

\subsubsection{Phase 2 (becoming operational): how do we sell?}

The product itself was clear now, but the remaining question was how to realise the business model in a viable way? What are the key activities and key resources on our side, and what do key partners do? The most challenging parts were: How to organise the high-quality and cost-efficient installation and maintenance of the PV systems, and how to distribute these efficiently in rural East Africa?

Meanwhile, we had also found a pilot-phase partner in Kenya and decided to run a second pilot with another 100 customers to test different service approaches with them.

\section{Ensuring proper system installation and after-sales service}

Since we had all been trained as engineers, we did the system installation ourselves in the beginning, but we quickly grasped that this would not be something feasible for a commercial roll-out. Our first move was to develop a plug and play kit that customers could install themselves. In co-creative sessions with real customers, we even managed to draft an accompanying manual. But we came to realise that even though our customers were now able to do the installation themselves, they simply did not want to. 'This is like having to put the engine into your new Mercedes-Benz!' is a quote from one of our pilot customers. People rather wanted someone knowledgeable to do the job. 


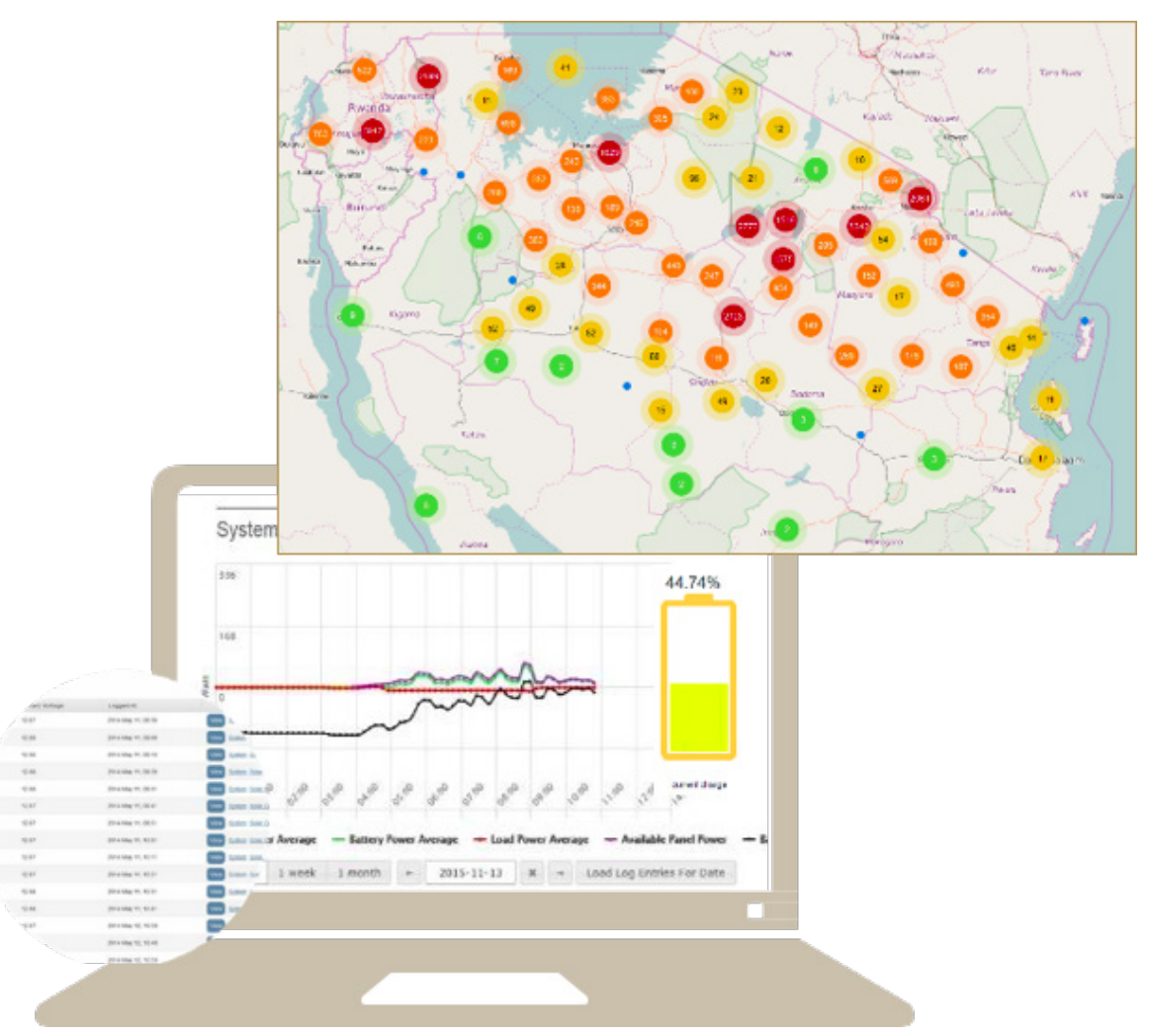

Figure 32: Mobisol's maintenance interface.

Source: Mobisol/Lindner (2017).

So we changed the approach and decided to bring local village technicians (who until then had been repairing houses, bikes, or phones) into the model. Through a two-week programme at the 'Mobisol Akademie', which we created for this purpose, they were trained and certified as Mobisol Installation Technicians.

After gaining some experience, the technician could later take another two-week training course and become a maintenance technician. The real-time performance and usage indicators from each system fuel an online database, which is our backbone for maintenance. A web-based interface makes it possible to coordinate technical activities in the village in an effective and viable way.

With that concept, we not only arrived at a feasible solution for us in the end, but we also made our customers even happier (they know and trust their local technicians more than foreign people) - and it created jobs in the village. 


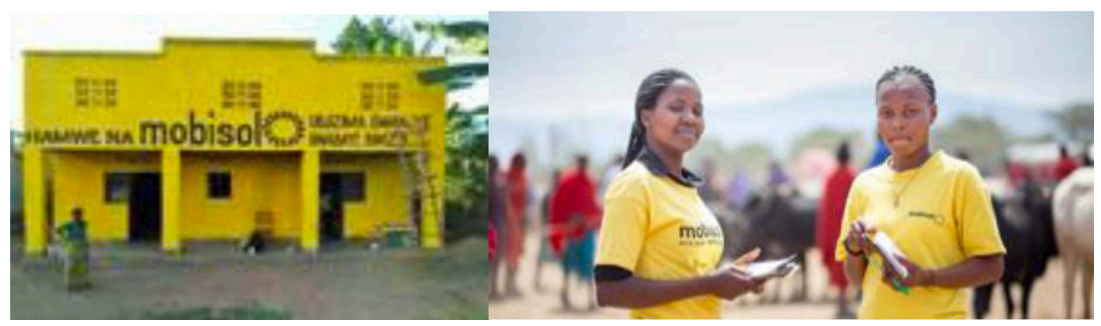

Figure 33: Mobisol's distribution centre and local promoters.

Source: Mobisol/Lindner (2017).

\section{Making sure that our customers gain access, no matter how remote their homes are}

To come up with a cost-efficient distribution strategy, we looked at informal markets for inspiration: When a Tanzanian family builds their new home, they go to the nearest market, buy the bricks, and find a means for transporting the materials home - sometimes a bus on the right route, sometimes a car, sometimes a boat. Every village then has a mason, who is hired to build the house.

We already had the local technician, so we started to build up a decentralised network of sales outlets. Today, we have our MobiShops at marketplaces that our customers regularly visit and make sure the packaging is optimised for easy transport. As soon as the papers are signed, our customers go out and cover the last mile themselves.

All sales activities are coordinated and monitored using a CRM system we developed in-house. Not only our customers use M-Pesa: We also deliver all our payments to staff digitally and thus have fewer transaction costs, less corruption, and a viable business.

\subsubsection{Phase 3 (commercial roll-out): how do we finance our growth?}

During our pilot phase, we had already dropped the idea that Mobisol could become a manufacturer or perhaps a wholesaler from which local distributors could buy in bulk and assume the point of contact for the end-user - these local distributors did not exist at the scale we needed. If we wanted to make this work, we thus had to extend our activities and build up our own structures. So the major remaining challenge was finding a way to pre-finance the hardware.

We wanted to work independent of subsidies or donor funds with a limited project life. We were aiming for a full commercial model.

Microfinance institutions seemed to be interesting key partners, but we quickly realised that, at least in sub-Saharan Africa, they only operated in cities and not in rural areas, where we envisioned our market. That meant we had to 
talk investors and banks into lending us a lot of money directly so that we could bridge those three years between the purchase and completion of payment.

We already had the switch-off mechanism that helped lenders to sleep better, but we still needed a way to carefully assess the creditworthiness of interested households. How do you do that without the equivalent of a Schufa credit rating and with a dynamic ability to pay? In several iterations, we came up with a credit survey that carefully assesses all potential income sources on the one hand, and all expenses on the other. Surprisingly, applicants have two to three income sources on average, and one of the most important questions to understand the expenses of a household was 'How many wives do you have?' Over time, we developed a double-check algorithm from the data we had gathered that allowed us to see who was trying to tweak the responses.

As the business evolved, we 'walked up the finance ladder': from angel investors and foundations in the beginning, to donor funds and impact investors, to finally becoming bankable and getting 'ordinary bank loans' from KfW Group, the German government-owned development bank, and the like.

\subsubsection{Phase 4: how to become a market leader?}

The year 2012 was all about piloting, prototyping, and iterating the business model. Then, in 2013, we sold 2500 systems in our Tanzanian market. In 2014 we opened Rwanda and sold 10,000 in total. In 2015 we started to scale and reached 25,000 households. In June 2016, we reached the symbolic moment of empowering household number 50,000 and by then had become one of the three major players in off-grid electrification in sub-Saharan Africa (the other two were M-Kopa and Offgrid Electric).

Currently, we are facing two new challenges: We are aiming to cross the 'chasm' of innovation between early adopters and mainstream customers, and we want to continue our regional expansion without having to simultaneously grow the company as well.

In contrast to markets of the Global North, so-called below-the-line marketing plays a much more important role than do above-the-line activities in our context (direct communication vs. TV and radio ads). Through our 'Project Saturation' we are currently developing marketing strategies tailored to different customer types and building long-term relationships with trustbuilding entities and influencers, such as schools, health care facilities, and religious communities.

In parallel to this vertical growth, our regional expansion team is aiming at finding the right partners to start joint ventures in new regions. Our main lesson learnt is that having experience with renewable energy technologies is not an important criterion. What is much more crucial is for the partner to share a similar mindset of engaging in a long-term - and at the same time commercial - relationship with customers. For example, a motorcycle vendor 


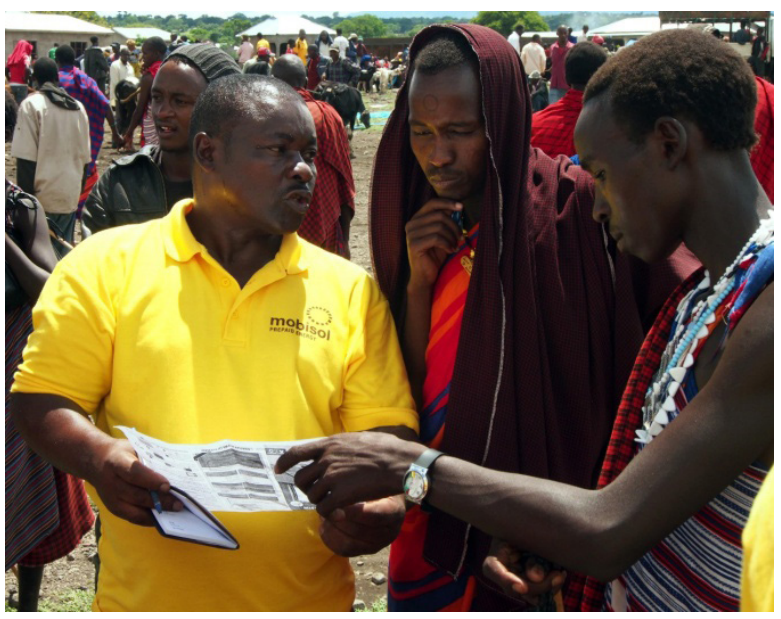

Figure 34: A Mobisol marketing officer meeting potential customers at a Maasai market in Tanzania.

Source: Mobisol/Lindner (2017).

that is active nation-wide could be our next partner. By developing a 'Mobisol Blueprint' or operational manual, we aim to bring that partner up to a working level quickly.

The outcome so far is that we are now selling about 4000 systems per month. After Rwanda, we are now starting operations in Kenya in a joint venture with a national car (and solar) battery distributor and have pilot systems set up in two more countries.

\subsubsection{Summary - finding new ways to serve the underserved}

For us, the so-called developing world is no barren land but a green field for innovation. Mobile phones, mobile banking, and renewable energy technologies are only the start, and we see a potential for leapfrogging in many more areas.

\section{A few things we are working on at the moment}

Seeing the radical uptake of smartphones, we have also created a customer app that increasingly serves as a lean interface between us and the customer. As we have gained a strong reputation for good quality and generally 'being there' in the village, we are starting to create a position as a 'gateway' between our customers and other product and service providers and are currently testing that with electrical appliances and health insurance. Our most radical R\&D project is targeted at overcoming the bad infrastructure in rural Africa. We 


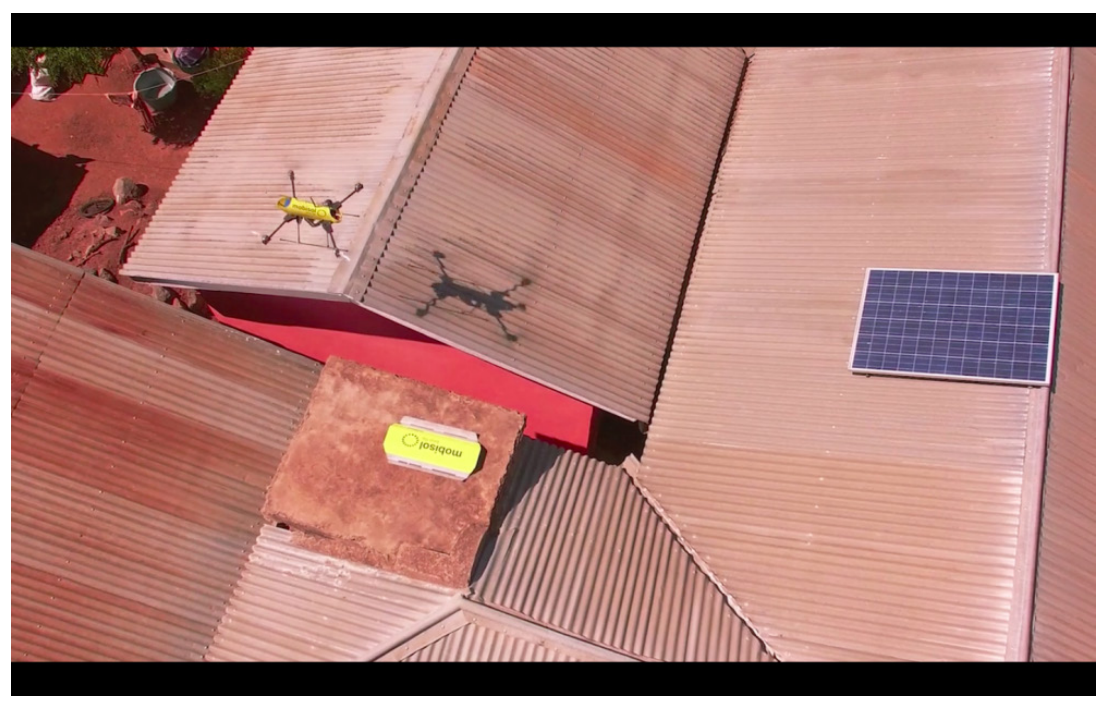

Figure 35: Mobisol drone landing on a customer house.

Source: Mobisol/Lindner (2017).

are currently testing a drone delivery network for spare parts, piggybacking on the ever-growing network of customer homes, which could serve as batteryrecharging stations.

\subsubsection{Author biography}

Klara Lindner strives to connect human-centred design with sustainable energy provision. She joined the solar company Mobisol in its infancy, led the pilot phase in East Africa, and co-developed its pioneering business model. Alongside improving Mobisol's customer experience, Klara became part of the research program Microenergy Systems in 2013, investigating service design in the bottom-of the-pyramid/energy context. As a certified Design

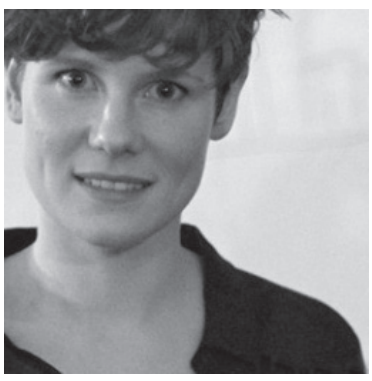
Thinking Coach, Klara has been using various workshop settings to teach creative thinking applicable to processes of innovation and change. 


\subsection{Solarkiosk: social enterprise and decentralised energy}

\section{Interview with Lars Krückeberg, Founding Partner of Solarkiosk, on January 18, 2016}

Solarkiosk enables and empowers the sustainable economic development of base-of-the-pyramid (BoP) communities world-wide through the provision of clean energy services, quality products, and sustainable solutions. Intertwining an award-winning technology solution with an inclusive business model, Solarkiosk fosters local entrepreneurship at the BoP. The first Solarkiosk project was successfully implemented in 2012. By the beginning of 2018, Solarkiosk had established six country subsidiaries and is involved with projects on three continents (Solarkiosk 2018).

\subsubsection{Technology and business model}

\section{Technology}

In our profession as architects, my partners and I are always keen on getting to know new, holistic approaches that step beyond the day-to-day business of an architecture workshop. The idea of providing decentralised energy via a kiosk resulted from the observation that informal markets exist all over sub-Saharan Africa, including areas beyond the grid, and kiosks are a familiar feature even in the most remote regions.

Typically, development projects in these regions include the construction of mini-grids, providing power to schools, selling solar lamps, etc. The organisations provide the hardware and then leave. As architects, we deal with energy from a perspective of sustainability - energy needed to construct a building, to operate and maintain it, to produce the materials needed for its construction, etc.

We looked at the idea of a kiosk from a purely technical point of view: What type of - not too heavy - building could be manufactured on an industrial scale, such that it could be transported anywhere, erected very easily, and, once erected, could produce power in a safe and sustainable manner while requiring low levels of maintenance? You have to imagine it as a 'power room' in which other commercial operations are also possible. We talk about last-mile distribution, both in retail and electricity production. This last mile is tricky, and that is why so few ventures have actually succeeded.

The idea was to develop a product that can adapt to any climate, can deliver clean energy in a sustainable way, is easy to transport, and is modular. That means it should be able to connect to other types of energy supply, such as wind or biomass, but it should also be extendable in a spatial dimension. 


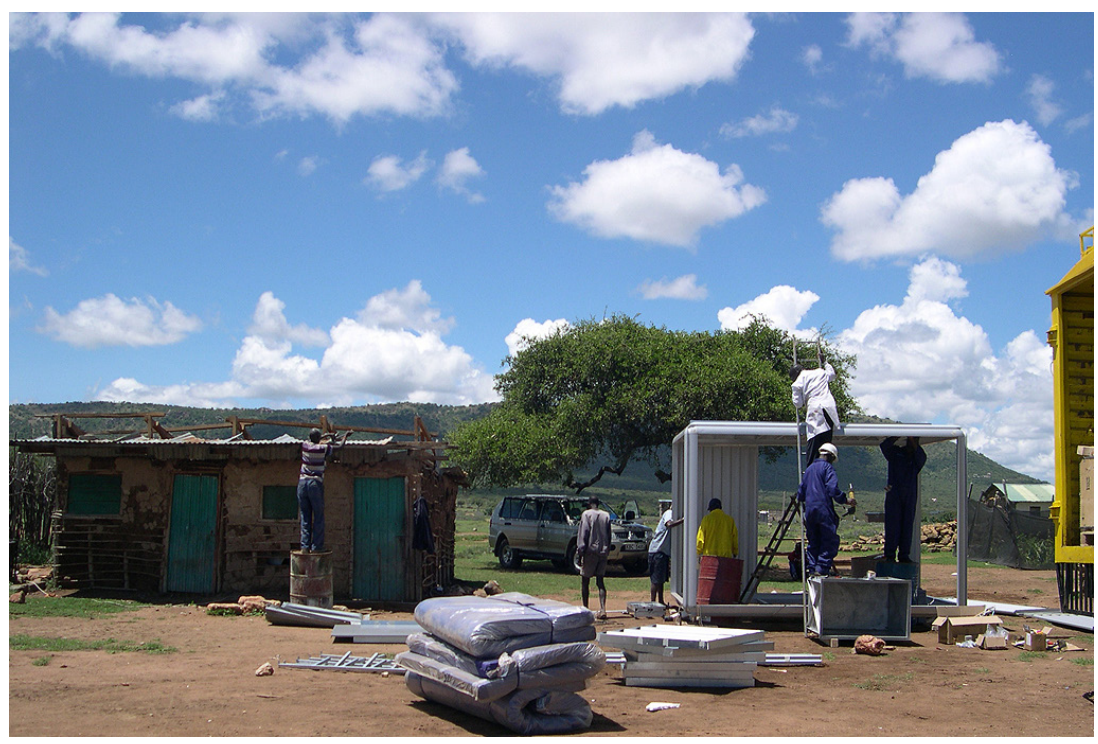

Figure 36: On-site construction of a Solarkiosk.

Source: Solarkiosk (2017).

We strive for an integrated solution in which architecture and solar power are so closely tied together that human error can be minimised.

\section{Business model}

We always had the vision that we wanted to have an impact, but a lasting impact can only be achieved if it is linked to a successful business model. We call it social business.

When we started, we perceived the world as being divided into two factions that have only since, say, 2014 converged: the business sector and the social sector. For the social sector, the premise existed that a project was not supposed to make a profit because it required ripping off the poor (although NGOs are also surviving on that). By contrast, the business sector does not care about social impact because it simply costs too much. The financial flows were separated accordingly.

It was very difficult to make people understand that, in this area, the combination of the two worlds is the only implementable option that allows for scalability. Many NGOs initiate great projects, but they are often hard to scale, and their financial sustainability is rarely achieved.

With a business approach, the social impact may not be the only focus. However, the projects reach acceptance levels that have a positive feedback effect on performance and, hence, the continuation and expansion of the project. 
Meanwhile, we started developing the business model for the kiosk - also based on the principle of modularity - and attracted the attention of one major investor who is active in solar energy. This investor allowed us to do a proof of concept.

Anyone who is familiar with the context of sub-Saharan Africa immediately realises that there is an immense business opportunity. These markets are very dynamic. Companies such as Mobisol and M-Kopa sell energy solutions that range from small lamps to proper solar home systems. The problem is that rural residents typically do not have any money and have to pay in instalments. The key to this business model lies in the financing system. M-Kopa is comparable to mobile banking service M-Pesa. There are currently deals being undertaken in the range of hundreds of millions of US dollars.

Similar to the kiosk, our business model is equally flexible. One has to gradually explore all the possibilities linked to it.

\subsubsection{History and organisation}

In Berlin, we have around 30 employees. Together with our six African affiliates, we now have a workforce of more than 100 people. Our subsidiaries are all locally registered companies.

It all began with a meeting between my partner, Wolfram Putz, and Andreas Spieß, who developed the idea of providing decentralised energy via a kiosk after making the observation that informal markets exist all over sub-Saharan Africa. Together with Wolfram Putz and Thomas Willemeit, we are the founders of the architectural practice GRAFT, with subsidiaries on several continents. We are currently building a children's hospital in Ethiopia and have been frequently visiting Ethiopia, which is our first project in sub-Saharan Africa. There we met Andreas Spieß, a lawyer from Berlin, who had founded a solar company called Solar23 in Addis Ababa in 2008, which is now one of the biggest solar system integrators in Ethiopia. Initially, Solar23 was a spinoff of Siemens: When Siemens closed down its operations in solar generation, some of its employees became entrepreneurs.

We started with Ethiopia, which is a fascinating but difficult and very bureaucratic market environment with high barriers to entry, especially for founding new companies. The population is very poor with limited buying power, even if they desperately need the electricity. Our assumption was that the poor would redirect the money that they would typically spend for 'dirty' energy, such as kerosene, diesel, or paraffin, to our cleaner and cheaper energy. No one in the world spends a higher proportion of their income for energy than those deprived people because these forms of energy - in particular diesel - become very expensive when they reach these remote areas. A cleaner source of energy has immediate influences on their lives because it makes them healthier and 
saves them money. The idea is that these people will slowly climb up the 'energy ladder'. In the beginning, a household may only have the financial resources to buy a pocket lamp, then comes a small home system, then a larger system, and so forth - up to the replacement of the diesel generator. The same is true not only for residential customers, but also for small businesses.

In Ethiopia and in Kenya, we delivered the proof that the concept actually works. We placed our kiosks literally at the end of the world to see whether people in these areas would accept them because there was no available data on such an endeavour. These are informal, but also untapped, markets. However, if you place half a dozen kiosks at the end of the world, the business is highly unprofitable because the supply chain is too expensive.

We tested in Ethiopia what would work and what would not work. We found the sites and operators and talked to the communities to get to know what locals really needed in order to create awareness, which was the task of our subsidiaries. We support them in marketing and give hints about best practices in other countries, but we learn from our operators and the agents in the field on a daily basis. Our local teams visit the kiosks up to one time per week to learn. However, scaling our business model, adding corporate functions and compliance mechanisms, optimising the logistics, etc., is all undertaken from our headquarters.

We started with the assumption that we have to convince people to come to the kiosk, which means we need traffic. So we have to offer something that people need. Once they have arrived at the kiosk, they realise there is light at night and see that solar power actually works. Meanwhile, we can offer cold drinks, play music, and provide a social space. We opted for fast-moving consumer goods - one pillar of our sales strategy. In addition, we offer special products related to hygiene. The second range of products relates to solar energy. That is where the impact actually starts! From a pocket lamp to a full-fledged home lighting system, we provide energy solutions for the residents.

The major problem is awareness: People will only buy what they are familiar with. Unfortunately, a first wave of cheap, low-quality products from China had destroyed confidence in solar products because they failed very rapidly.

The third business line for our kiosks is energy services. When the kiosk generates electricity to operate its point of sale - including having the lights, a small computer, and a solar fridge on - the kiosk can sell its excess production to other businesses connected to the kiosk. Alternatively, we can use the excess electricity for entertainment, for example for TV. The TV can then be transformed into a small cinema, and the operator of the kiosk can charge an entry fee to show football. We provide mobile phone banking, phone charging, internet services, and much more.

We had to take into account the need to achieve community acceptance: Who are the stakeholders in the community? What do the people in a particular community actually need? What are they interested in? And how to 


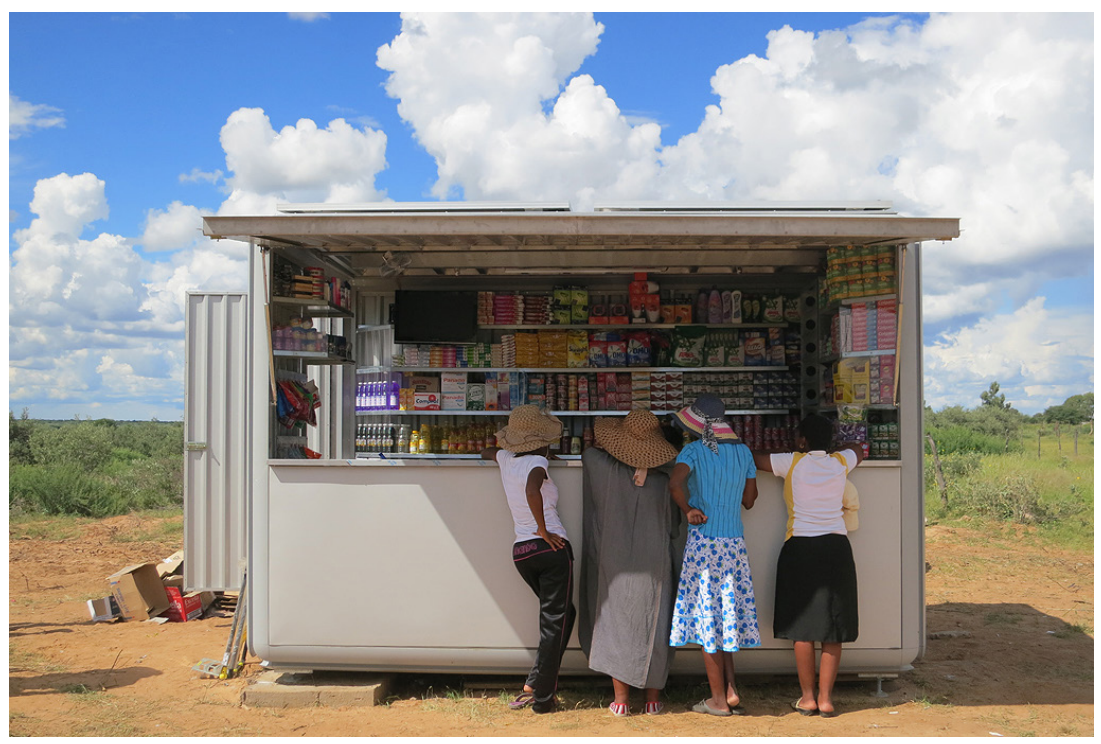

Figure 37: A Solarkiosk in Botswana.

Source: Solarkiosk (2017).

create awareness? We had to start becoming retailers as well as experts in marketing and things we never dealt with before. We realised that we could not start at the end of the world, but rather that we had to expand outwards in rings and clusters.

We then founded a joint venture with a family in Botswana that operates one of the largest franchise chains in sub-Saharan Africa - real retail professionals. They showed us how retail in Africa is functioning. The first thing that they decided was that all goods and products that are delivered to - and sold at - a kiosk pass via the point of sale; everything that comes in and goes out is controlled. In fact, a kiosk cannot be successful without this control, otherwise there may be theft. We sharpened our understanding of how to maintain close ties with our operators. We do not employ them - we would rather create a partnership with them and formulate precise contracts. We would not sell our kiosks because they would be too expensive. However, we would enable local entrepreneurs to start a business with it and create an environment where other businesses would also flourish in order to create an impact on the entire community.

We discovered that the platform, that is, the kiosk, has a certain value to others and they are willing to buy it. This became our second pillar for revenues - a cross-financing tool, if you will - and enabled us to finance our expansion, which is quite capital-intensive, as well as improvements to the system. 
Wherever a kiosk is established, other businesses emerge, too. We started to introduce fast-food services. Our clean-cooking stoves have a fundamentally positive health and environmental impact, in particular with regards to deforestation. The operators will pay us rent for the equipment; they are like a franchise.

Now we are learning how a kiosk is the nucleus and trigger for other ventures, such as rental space, a cinema, and connectivity. We just signed a partnership with SES, the largest satellite provider in the world, headquartered in Luxemburg. With their support, we can bring the internet to the most remote places in the world. Of course, that is more expensive than a landline, but one of the criteria for the locations of our kiosks is the very absence of functioning transport, energy, and telecommunications infrastructure. In those areas, quantum leaps are possible, as telecommunications has demonstrated. It is not astonishing that Google, Amazon, Richard Branson, and Elon Musk have spent billions of dollars to reach these remote markets. It is a positive development to provide these people access to goods and information. But it is also a gigantic business opportunity. For that type of infrastructure, a person in charge has to be on site to market and sell this offer. People then also need devices to access the internet, and these devices have to be charged. When spending all these billions in space technology, investors expect these services to emerge automatically, but that is not the case. Rather, they have to be initiated by organisations such as Solarkiosk. We are an analogue road to market, but we pave the digital road to market.

A kiosk typically creates about four new jobs. Our operators start earning money from day one of the operation of the kiosk. But we want to break even jointly for all the kiosks in a country, and also for our headquarters in Berlin. That is only possible via scale, whereby we can increase our buying power, accommodate the high capital expenditure, and seize other opportunities because of our position as a monopoly provider. Our business plan is to break even within the next five years, but we have to build more than a thousand

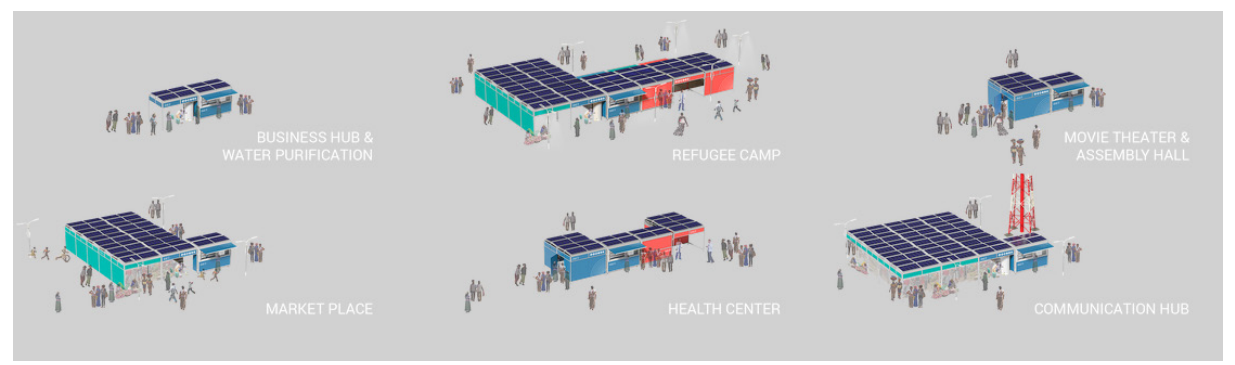

Figure 38: Potential use cases of a Solarkiosk.

Source: Solarkiosk (2017). 
kiosks to reach that target. To do so, you have to acquire the finance and find the people who believe in our venture.

\subsubsection{Scaling and cooperations}

We first worked together with a US software company, but we did not like that the data was being stored in the United States, and it was not available in all countries where we wanted to operate. We then decided to purchase software developed in the respective countries, but the software was mostly targeted towards supermarkets as customers. For the informal market, solutions did not exist. People just counted the money themselves. So we came to the conclusion that we had to develop our own software and purchase the corresponding hardware.

We went to international conferences and presented our model. At that time, we had around 15 kiosks in three countries in operation. We soon realised that interested people were approaching us because we had a unique selling proposition.

The European Union, USAID, and the World Bank started to allow for private-sector involvement in their projects or to explicitly integrate it. For example, the EU's Electrify programme started to steer major financial resources towards the private sector - money that, in previous times, would have been exclusively reserved for NGOs. The decision makers redefined their ideas about social enterprise. Large investment funds were approaching us, too. At the same time, representatives of multinational corporations were approaching us. They were either from the fast-moving consumer goods sector, or they were companies from the energy sector with a profound knowledge of the African business context, namely Coca-Cola and Total.

In order to secure their future markets, Coca-Cola tried to develop something similar to our idea. They called it EKOCENTER, but it did not work. It also evolved from the idea of a social enterprise - a triangular relationship between government, business, and NGOs. This idea is not in the context of corporate social responsibility, but rather a profitable business that enables and empowers people. They painted a large container in red and added a massive number of gadgets and functions. In August 2013, their CEO and Chairman, Muhtar Kent, announced the launch of the first EKOCENTER in South Africa. Soon afterwards, they realised that it was just way too expensive. They actively searched for alternative solutions and found us: 'If you can't beat them, join them!' So we did a pilot with 25 kiosks with them in countries where we were already operating, as well as three new countries. The pilot was a success. Then we started phase 2 with 150 kiosks, which is ongoing. In the meantime, they have seriously started investing in our organisation and venture, and they believe in it.

The cooperation was based on the following agreement: We own the assets, we put them on site, we operate them and do the business. But EKOCENTER is 
present for all decisions, we decide together on how to improve the operations, and the kiosks are branded 'EKOCENTER powered by Solarkiosk. For them, it is important to establish their EKOCENTER brand. Of course, we sell Coke in these kiosks. They are interested in developing village concepts with a focus on the social dimension by electrifying schools and medical dispensaries as well as a particular focus on water purification - a powerful lever for the physical and economic health of a continent. We could do that on our own - we even founded a charity together with the Siemens Foundation that focusses on water purification in Africa: the Solar Fountain GmbH. However, I do not personally believe that it is a viable business model. I am rather convinced that water supply should not be a commercial service to make a profit. Water is essential for survival, but electricity is not.

The other business partner that approached us early on was Total. We launched two pilot kiosks with them in Kenya. In the meantime, we have sold more kiosks to Total. We also sold 18 kiosks to Coca-Cola. There are some regions where we see no business potential but our partners do. There is exclusivity - maybe one day we will decide to tackle these regions, too. But for the moment, we just install the kiosks there and then leave the operations to our partners.

At the end of 2016, we had around 200 kiosks that are operated by us in six different countries. From the other kiosks, we can still learn. We are still in the learning process about cost optimisation and the lean management of retail space. The supply chain logistics are still a major bottleneck. The other one is

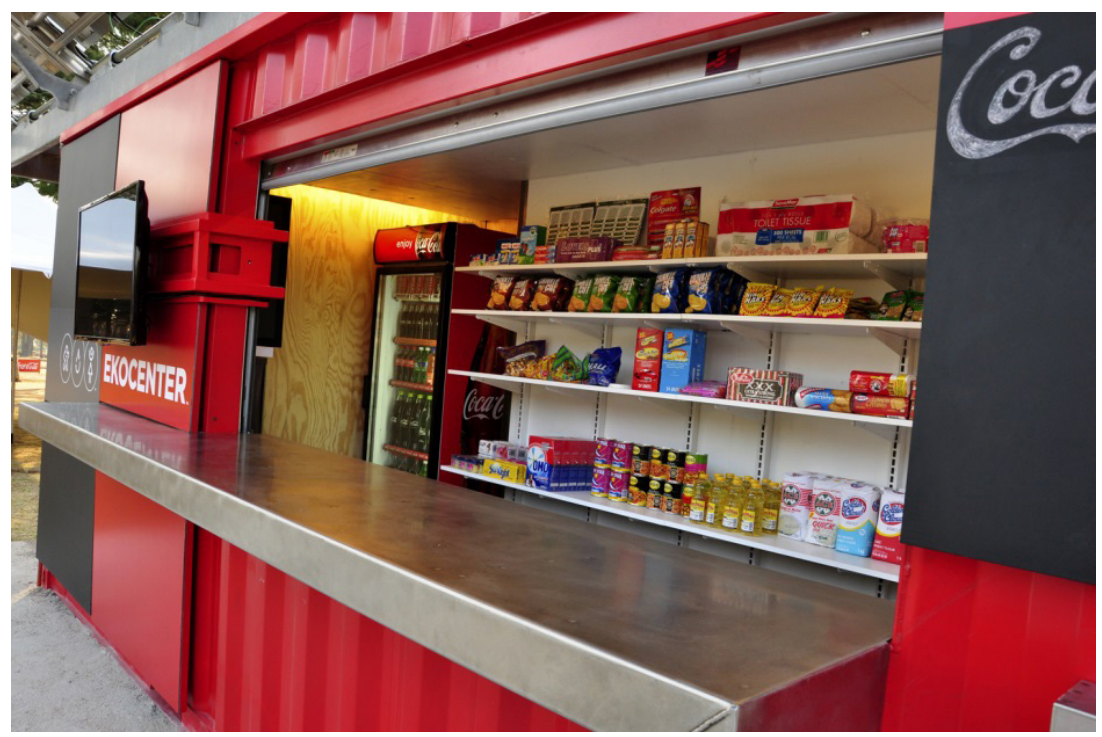

Figure 39: Coca-Cola's EKOCENTER.

Source: The Coca-Cola Company (2017). 
human capacity: Where do I find the right operators in Africa who can deal with the retail challenges, the marketing and technological challenges, as well as the real-estate dimension at the same time?

More recently, we started a pilot project with Coca-Cola and Ericsson in Rwanda. We provide energy and rent out the area for a telecommunications tower. In return, we pay for their internet service provider and the data used. These are complementary services. Customers who come to eat and drink at the kiosk may also want to use the internet. These types of experimental settings could be called 'de-risking'. The bottleneck is always the human factor: Which operators are capable of handling such a complex service? How to find entrepreneurs who are both loyal and realise their own ideas on top of our business, ideally women? They have to be sales agents, and sometimes they have to employ additional staff. Finding the right site for the location of the kiosk is equally challenging: even the best entrepreneur fails if the location is not carefully chosen because no traffic emerges. It is also difficult to transport the kiosk into the countries, so we have set up local manufacturing units. Often the prices are lower when components are imported than if they are produced locally. But it is essential to have the option of producing components locally.

We started with Ethiopia, Kenya, and Botswana. Later we added Rwanda, Tanzania, and Ghana. There are also kiosks now in Vietnam. We won an EU tender and are now building 40 kiosks in Ethiopia and 40 in Kenya with EU funding and using a local manufacturing workforce.

We started developing products for Connected Solar Clinics and Connected Solar Schools, in particular for governments and the United Nations. In early 2016, we launched a Connected Solar School in the Jordanian refugee camp Zaatari, together with SES. We donated the Solar School, but we are convinced that there will be business opportunities in the future. Energy access for refugees is essential, but connectivity is equally important, especially for education. The Connected Solar Clinic was built in the Jordanian region of Al-Mafraq, which hosts many Syrian refugees. Up to 30 per cent of the population there consists of refugees. We want to show that energy and connectivity are a solution for - let's face it - the new cities of the world. That type of infrastructure could potentially be built in any slum or informal settlement around the world. It is particularly useful if water purification is added.

We offer a piece of infrastructure for the cities of tomorrow because it can become the nucleus of urban development due to its modular design. It can become a mini-shopping mall, a place for assemblies, even a security post because of the connectivity. There are an infinite amount of possibilities and synergies. We can imagine building a complete neighbourhood around a kiosk. Our advantage is that we provide the nucleus for clusters of businesses and ideas. We provide the platform to create new jobs and promote the local economy.

Of course, we do not want to stay in Africa. We plan to expand to Latin America and Asia, but we have to proceed step by step. We would not survive 
by becoming too big too fast. We first have to develop deeper roots in the territories where we are operating.

As soon as we are able to enter the wholesale business, everything will change.

\subsubsection{Market outlook and competitive environment}

One of our main competitive advantages is that we have successfully established the infrastructure and matrix organisation within the different countries. No competitor is able to replicate these structures so easily. Especially China has a strong strategic interest in Africa, but it tends to lack the soft skills. The confidence of the communities is the key to success. That is why the multinationals turn to us, and without them it would not work. We would not prevent anyone from imitating us, but the model is very tricky in its implementation.

\subsubsection{Interviewee biography}

Lars Krückeberg, M.Arch, Dipl.-Ing. Arch, Architekt $B D A$, Founding Partner of GRAFT

Lars Krückeberg studied architecture at the Technical University Braunschweig, Germany, the Universitá degli Studi di Firenze, Italy, and the German Institute for History of Art, Firenze, Italy. He graduated as Dipl.Ing. Arch in Braunschweig and received his Master of Architecture at the Southern Californian Institute of Architecture SCI Arc, Los Angeles, USA.

In 1998 Krückeberg established GRAFT in Los

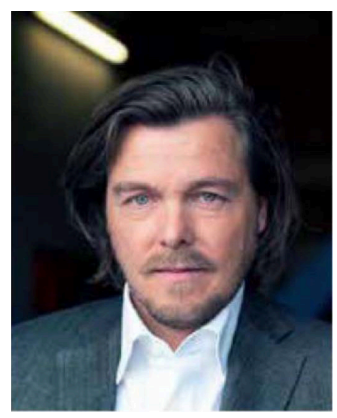
Angeles together with Wolfram Putz and Thomas Willemeit. With additional offices in Berlin and Beijing, GRAFT has been commissioned to design and manage a wide range of projects in multiple disciplines and locations. GRAFT has won numerous national and international awards and earned an international reputation throughout its 15 year existence.

In 2009 he co-founded Solarkiosk GmbH together with Putz, Willemeit, and Andreas Spiess in Berlin and manages the company as acting CTO. Since 2012, affiliate companies have been incorporated in Ethiopia, Kenya, Botswana, Tanzania, Rwanda, and Ghana.

\subsubsection{References}

Solarkiosk. (2018), SOLARKIOSK - enable. Empower. Retrieved February 10, 2018, from http://solarkiosk.eu/company/ 


\title{
3.9 Power Ledger: peer-to-peer trading with Blockchain as decentralised transaction technology
}

\author{
Interview with Jemma Green, co-founder and chair of Power Ledger, on \\ August 25, 2017
}

Power Ledger uses blockchain technology to enable households and buildings to trade excess renewable energy peer to peer to make power more distributable and sustainable for consumers. The Power Ledger system tracks the generation and consumption of all trading participants and settles energy trades on predetermined terms and conditions in near real time.

In October 2017, Power Ledger raised A $\$ 34$ million through its POWR Token Generation Event. More than 15,000 buyers took part in Australia's first Initial Coin Offering, with the Main Sale following a successful Pre-Sale at the start of September that saw the company raise A $\$ 17$ million in just 72 hours (Power Ledger 2017).

\subsubsection{Technology and business model}

\section{Technology}

Of all blockchain start-ups in the energy sector, Power Ledger has advanced the peer-to-peer trading environment the most. Power Ledger facilitates peerto-peer energy trading - a concept by which renewable energy can be sold between buyers and sellers. This is an innovative business model capable of disrupting incumbent utility companies. Power Ledger has a unique service offering, as we partner with utilities, allowing them to on-board their customers to the platform. We call it 'phased disruption', and the response from the market has been very positive.

As for the technology, Power Ledger utilises blockchain technology, which is a secure, immutable, and transparent database. Because the platform manages financial transactions, the security of the database is crucial. The ledger is distributed across many nodes (versions of the database that are continually shared and reconciled to reflect the same ledger). Blockchain technology is also cheaper and faster than traditional databases, which is necessary, as energy trading requires millions of transactions.

Our software, which is already live, connects to Smart Metres and brings the data into EcoChain, our proof-of-stake private blockchain.

For peer-to-peer trading, the platform is able to register and settle transactions. Within a block of flats, for example, the platform allocates electricity to 
each flat and enables residents to sell their excess electricity to their neighbours. Our two-token structure enables us to process payments in the resident's local currency rather than through cryptocurrencies. In this instance, people can load funds onto the platform, which is linked to a credit system called Sparkz. This enables consumers to use Sparkz to purchase electricity or for a producer to sell it. Then they are able to convert the Sparkz back to dollars or any other fiat currency $y^{55}$ customers do not need cryptocurrencies or Bitcoin at all. The only parties that need to access our POWR tokens directly are our application hosts.

The validation is performed via a proof-of-stake blockchain - it has a quick block time, can be used in any energy market, and was purpose-built for highvolume transactions.

We also have a product called Asset Germination Events, whereby consumers buy, hold, and trade fractional ownership of large renewable energy assets, such as batteries or solar farms, using our platform. For example, a solar farm could use the blockchain to issue ownership. If someone owns 3.7 per cent of that asset, then that person would receive 3.7 per cent of the revenue.

For the solar farm to connect to the grid, the operator would need a power purchase agreement, but by using the blockchain, they can sell to many more consumers. At the same time, a building might purchase electricity from their own solar farms down the road to manage that energy transaction.

Blockchain gives us the ability to transition to a low-cost, low-carbon, and resilient energy system. This makes the grid more resilient, because by using blockchain, we can create localised energy systems and enable consumers to access electricity from a diverse number of sources. Today, households with solar panels can sell their excess energy to a utility company, which then sells it to others. The energy goes back to the grid and may have to travel far before reaching its destination. Our platform allows solar panel owners to sell their energy to those closest to them, which means the energy does not have to travel as far.

With respect to data privacy, residents are not forced to participate in our scheme, but they could if they wanted to - and they would be remunerated for it. We had cases where consumers were offered $A \$ 25$ to turn off their devices during peak demand. Of course, there are security concerns, but using blockchain technology mitigates this risk, as everything can be encrypted and anonymised. Blockchain is actually the solution to these concerns.

\section{Business model}

Power Ledger earns money via a daily fixed supply charge. We collect a small amount of revenue from each kilowatt hour sold. With the peer-to-peer trading,

${ }_{55}$ According to Investopedia, fiat money is currency that a government has declared to be legal tender, but it is not backed by a physical commodity. 
there is also a premium on each kilowatt hour sold, like a transaction fee. The supply charge varies and depends on the daily fixed supply charge set by the retailers in the marketplace, so it is benchmarked against that. By contrast, the peer-to-peer trading charge depends on the volume of the market. For example, we charge lower fees for higher voltage.

The tenant in a flat pays the electricity bill to the landlord. If the owner has rooftop solar, it provides them with an income stream and a return on investment for the solar panels and the battery. A solar system offers a return on investment of around 25 per cent in Australia. But homeowners can also purchase differential power if they do not have sufficient solar power in their systems. Owners can also purchase electricity on the wholesale market and then sell it at retail cost to the tenants.

Australian legislation allows us to operate embedded networks within buildings and enables us to do trials for 1.5 per cent of the turnover of a company without an exemption. Thereafter, we can apply for exemptions from the regulator to conduct larger trials.

At the moment, we offer a flat rate for electricity. If the right pricing is in place taking into account the time of day - a rooftop producer may be remunerated for it. Even when you are uploading solar power during the peak period, you would not be adequately compensated.

\subsubsection{History and organisation}

In May 2017, we had nine staff members in our company, including blockchain developers and experts. Since that time, we have grown to about 20 staff members, which includes energy experts, energy economists, and regulatory specialists. In addition, we have hired a business development team, a legal advisor specialising in blockchain issues, a chief operating officer, as well as added to our user interface and user experience (UX/UI) capabilities.

\subsubsection{Scaling and cooperations}

The first peer-to-peer trading project we did was in Busselton, south of Perth. That project ran from September to December 2016. The second project with peer-to-peer technology - a trial with 500 sites - was in Auckland with Vector Limited and started in December 2016. In March 2017, we started the Gen Y Housing Project, which is a block of flats in Perth. In addition, we have signed deals with BCPG, one of the largest solar Independent Power Producers in Thailand, Tech Mahindra in India. In Europe, the Liechtenstein Institute for Strategic Development (LISD) will become the first Application Host to offer Power Ledger's blockchain-based peer-to-peer energy trading platform 
in Europe, and we are part of a Smart Cities project in Fremantle, which is partially funded by the Australian government.

There are lots of opportunities in Asia and Africa. In developing countries, the Power Ledger platform can provide a modern, low-cost, low-carbon alternative to the traditional energy-supply model. Even better, because of the ability to fractionalise an asset, the platform can give communities and individuals a chance to own a share in their local power-generating assets. Regulated markets such as those in California, New York, continental Europe, the United Kingdom, Germany, Italy, and Austria would also be of interest to us.

For the most part, utilities are aware that something needs to change. We want the Power Ledger platform to disrupt the energy industry, not to destroy its value, so we are working closely with traditional energy providers to demonstrate new ways for them to stay relevant. Network operators need to find a way to keep people from defecting from the grid, and retailers need to find ways of connecting with their customers - so we are helping them achieve that.

The retailers we speak with realise that whether Power Ledger had come along or not, change would have happened - more renewables and grid defection, for example. There is also a lot of customer churn. One way for retailers to have a longer-lasting relationship with their customers is to offer peer-topeer trading. It is effectively cannibalising their incumbent market, but if they do not do it, someone else will. I think they realise disruption is inevitable for them, but the suffering is optional.

Our relationship with these utilities is not tense, but sometimes apprehensive. You need to demonstrate and persuade 20 people, sometimes more, before you can move forward with a deal. We are creating a new market, which means we need to have a number of conversations, explain what the blockchain is, and get people comfortable with the company before moving forward. It is a long engagement process.

The retailer landscape is very diverse. We have not been met with any hostile responses, but it does seem that the smaller retailers have generally been more responsive. In addition, there are some IT and electric vehicle companies involved as well as universities.

\subsubsection{Market outlook and competitive environment}

Our regulator, AEMO, hired Audrey Zibelman, who was previously the chair of the New York Public Service Commission and who has done a lot of work to manage that transition from a centralised to a hybridised system. That kind of market reform needs to happen in order to enable the technology to be deployed, not just by disrupting the technology but by managing the system resiliently during the transition. There is quite a lot of market reform that needs to happen, but there seem to be positive sentiments about renewable energies, with a couple of exceptions. For example, South Australia, where they have a 
high penetration of rooftop solar systems, endured blackouts last year. It was a big political issue. The government said that renewables were to blame, but in my opinion, it was actually a problem with the software and interconnectors. The argument that politicians put forward was that we should have fewer renewables.

This resulted in Elon Musk offering to put a big battery into the South Australian grid to show how renewables could solve the issue. Musk spoke with our prime minister and the South Australian government. Now the government has announced that batteries will be part of the solution, and that it is not just turning on more gas-fired power stations. The other part of the discussion concerns carbon emissions. Companies can just go on polluting, which means it is not a level playing field. We really need an instrument such as a baseline credit scheme or a carbon tax to address this issue. Politically, it has become a hot potato, and no one wants to touch it, but it needs to be addressed, along with a reform of the electricity market.

\subsubsection{Interviewee biography}

Jemma Green, Chair of Power Ledger Pty Ltd, is a member of the board of directors

Dr Jemma Green has more than 15 years of experience in finance and risk advisory, having worked for 11 years in investment banking in London. Whilst there, she completed a master's degree and two postgraduate diplomas from Cambridge University.

Jemma is a research fellow at the Curtin University Sustainability Policy (CUSP) Institute.

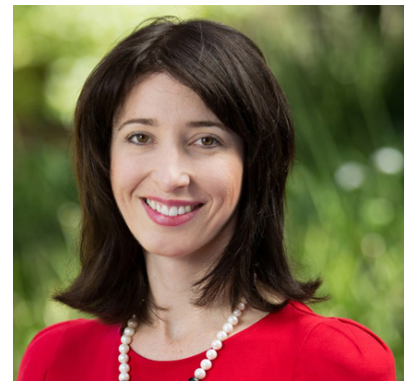
Her doctoral research into 'Citizen Utilities' has produced unique insights into the challenges and opportunities for the deployment of rooftop solar PV and battery storage within multi-unit developments and the application of the blockchain.

Jemma is also experienced in the challenges of sustainable cities through her role as an independent Councillor of the City of Perth.

\subsubsection{References}

Power Ledger. (2017), Power Ledger token generation event. Retrieved November 27, 2017, from https://powerledger.io/ 


\subsection{Core competencies in the energy transition - insights for corporate and political decision makers}

The conclusions of this chapter follow a dual structure. In the first part, the authors establish a categorisation of business models based on the conducted interviews and the contribution by Klara Lindner on Mobisol. In the second part, six core competencies for decision makers are derived from the interviews.

\subsubsection{Three new business models for dealing with the energy transformation}

Taxonomies of business models have seen widespread use to classify ways that companies generate money. One of the most holistic attempts is suggested by Gassmann et al. (2014). The authors claim that 55 business models are responsible for 90 per cent of the world's most successful businesses (ibid.), ranging from classical models such as franchising and multi-sided platforms to digital models such as freemium and crowdsourcing. By contrast, Hamwi and Lizarralde (2017) outline three major business models they observe in the energy transition: 'Customer-owned product-centered business models, where customers own the product related to the electricity generation or management; third-party service-centered business models, where a third party offers energy services to the customer; and energy community business models, where resources are pooled and shared between community members' (ibid.).

The seven interviews and contributions of the founders and executives of start-ups serve as an empirical basis to develop a taxonomy that bears similarities to what is described by Hamwi and Lizarralde (2017), albeit we chose a different terminology that takes into account the blend of regulated and non-regulated elements of the value chain, and its role as part of so-called 'critical infrastructure.

The following three business models can be derived from the analysis:

- New asset-ownership models: the start-ups SOLshare and Mobisol enable private energy consumers to become self-producers. Via different financing schemes, their customers will eventually own the devices they are using.

- New service and operating models: the start-ups Envio Systems and Solarkiosk as well as Timo Leukefeld's energy-efficient buildings belong to this category. In all three cases, services to establish or improve energy use are offered to final customers or intermediaries. Envio Systems builds on the existing energy supply infrastructure and specificities of each commercial dwelling to increase its energy efficiency. Solarkiosk rents its kiosks to 
local operators and lets them decide which services they want to offer to their customers. The tenants who occupy Leukefeld's single or multi-family houses pay rent to the building agencies, banks, or utilities that are financing and constructing the buildings.

- New platform models: for the first two business models, continuity can be observed, stretching from the first attempts of liberalisation to full-fledged decentralisation. The platform models, however, are an offspring of digitalisation, which allows for new markets of buyers and sellers of certain products and services. Entelios (in the area of Demand Response) and Power Ledger (in peer-to-peer trading) fulfil that role. They do not enable consumers to acquire assets, nor do they rent any devices or own any assets themselves. They only provide the intelligence to coordinate the assets that belong to their customers.

Combining the three phases of the energy transformation with the taxonomy of business models, Figure 40 shows the categorisation along the two dimensions.

In the following sections, the three types of business models are presented in greater detail and complemented by additional examples.

\section{New asset-ownership models}

Together with the water supply, transport, telecommunications, and waste management sectors, the energy sector - in particular, the grid-based infrastructure

\begin{tabular}{ccc|}
\hline $\begin{array}{c}\text { Phase I } \\
\text { (Energiewende 1.0) }\end{array}$ & $\begin{array}{c}\text { Phase II } \\
\text { (Energiewende 2.0) }\end{array}$ & $\begin{array}{c}\text { Phase III } \\
\text { (Energiewende 3.0) }\end{array}$ \\
\hline Grid-based and connected & Partially autonomous & Fully autonomous \\
\hline
\end{tabular}

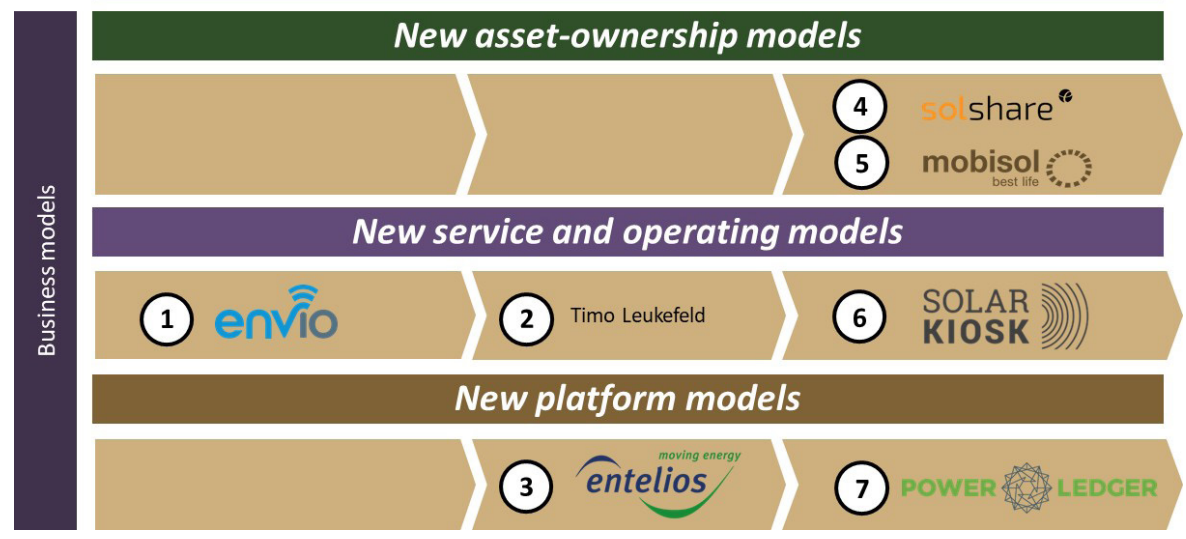

Figure 40: Business models and phases of the energy transformation Source: Authors' contribution. 
of electricity and natural gas supply - requires capital-intensive investments up front to establish pipelines and transmission lines; generation plants and transformers; metering devices at the final users' residences; data and billing centres; and many more technical features.

In the traditional configuration of the electricity supply industry, assets were owned by the state, state-owned enterprises and municipalities, or by regulated private entities. Following the rapid expansion of energy demand in the 1980s and 1990s - especially in developing countries - new entrants from the private sector were able to build, own, and operate - or to build, own, and transfer - assets under long-term contracts with utilities. Simultaneously, many countries in the Western hemisphere started liberalising their power and gas sectors and opened parts of the value chain to competition, especially generation and retail.

Since liberalisation, the public ownership of assets has decreased. The large-scale privatisation of distribution and generation first occurred in Latin America and the Caribbean - starting with Chile under Pinochet in the 1980s followed by Eastern Europe and Central Asia after the fall of Communism in the 1990s and 2000s.

Privatisation typically implied transferring ownership from a public enterprise to a multinational investor or utility that would take over the assets. For example, European energy incumbents such as Finnish utility Fortum, German E.ON, or Italian Enel entered the Russian market when the state-owned assets were sold. However, with liberalisation, a substantial number of new players entered the electricity market. In particular, newly created wholesale markets encouraged traders to start dealing with electricity and natural gas as commodities; insurance and hedging instruments were offered by players from the financial services world. In these cases, they would not own the assets.

The most fundamental change in terms of ownership occurred with the rise of decentralised energy. By incentivising PV installations with feed-in tariffs, homeowners, farmers, and energy cooperatives were encouraged to install PV panels or wind turbines. Ownership of power-generating assets became a mass-market phenomenon.

Australia has become the world leader in rooftop solar, with more than one solar panel per inhabitant (Stock, Stock \& Bourne 2017: 7, also see the country profile in this book). At the end of 2016, Germany had more than 1.5 million privately operated PV plants (BMWi 2017) and around 27,000 wind turbines (BWE 2017), all of which were overwhelmingly owned by private entities.

Between 2012 and mid-2016, the United States experienced almost uninterrupted growth in residential PV installations (Perea 2017), reaching around 2.3 GW in 2017. Forecasts of consulting practice GTM Research estimate this capacity will grow to more than $4 \mathrm{GW}$ in 2022 (ibid.).

Asset ownership can also materialise in energy associations or energy cooperatives. By contributing a certain amount of money, citizens who do 
not have the possibility to set up renewable-energy facilities on their land or rooftops can donate a certain amount of money and participate in an association. In Germany, the number of energy associations rose from 66 in 2001 to more than 850 in 2017, and total membership is around 180,000 and growing (Bundesgeschäftsstelle Energiegenossenschaften 2017). A survey by the German Cooperative and Raiffeisen Confederation DGRV (2015) reveals that more than a fifth of the members pay $€ 1000$ or less to become part of the association, and around a third pay between $€ 1000$ and $€ 3000$. Hence, even for people with smaller budgets, it is easy to be a co-owner of a PV plant or a wind turbine.

Energy associations typically have a geographical proximity to their assets. They are often part of a local initiative, with residents, regional banks, and even municipalities sometimes serving as the driving forces. Meanwhile, digitalisation has made it possible to detach ownership from location. Over the last decade, crowdsourcing platforms have mushroomed, often to raise money for cash-strapped entrepreneurs. The most popular platform was Kickstarter, through which the creators of the Fairphone as well as Elon Musk and his electric car company, Tesla, raised money for their ventures. Crowdfunding typically follows a simple principle: anyone in the world is invited to invest money in a certain project - often as an upfront investment - and receive a product or service during the later stages of the venture. In the energy sector, crowdfunding platforms such as 'crowdener.gy' or 'econeers' raise money for specific projects, most often in the field of renewable energies.

Asset ownership, hence, has become a globally dispersed phenomenon. As opposed to donations to charities or non-governmental organisations, in crowdfunding the intermediary is digitalised - donors and receivers directly interact with each other.

In the near future, though, asset ownership may advance to the sphere of cryptocurrencies and decentralised ledger protocols such as blockchain. Owning real assets with a virtual currency sounds like a logical inconsistency. However, the value of a cryptocurrency is based on a consensus of the value of the currency among those who have invested in it. It is a system of faith and speculation, similar to most market-based assets.

The buzz term in this dimension is 'initial coin offering' (ICO). In an ICO, the issuer offers so-called tokens (Orcutt 2017). A token can represent a certain amount of a virtual currency, but it can also be cloud storage space, as in the start-up Filecoin, or it can correspond more closely to traditional stocks of the issuing firm, as in decentralised autonomous organisations (or DAO, see Burger et al. 2016 for a discussion). In the energy industry, Australian start-up Power Ledger raised US\$24 million in October 2017. Around 15,000 supporters invested in the ICO. Power Ledger's tokens are called POWRs and are convertible into Sparkz, which is the virtual currency for Power Ledger's users to trade electricity among themselves (St. John 2017). Another 
application suggested by Power Ledger is 'autonomous asset management'. According to information issued for Power Ledger's token generation event in October 2017, this application provides a platform for shared ownership of renewable-energy assets as well as for trading renewable-asset ownership (Power Ledger 2017).

Of course, ICOs in the energy sector are still niche applications of a niche technology. In addition, public authorities such as the US Securities and Exchange Commission and, in the case of Power Ledger, the Australian Securities and Investments Commission (ASIC) are exploring how to deal with ICOs from a regulatory perspective. For example, ASIC interprets ICOs as a type of 'Managed Investment Scheme and therefore subject to the Australian Corporations Act' (Thomsen 2017). With multiple applications foreseeable, ICOs may become the virtual mirror image of the dispersed ownership of decentralised energy assets.

Sebastian Groh's insights from Bangladesh reveal that decentralised asset ownership can be particularly advantageous in the context of developing countries, where a connection to the central grid represents a certain elevation in social status, but may also coincide with a lower quality of power supply because of multiple interruptions. He observes that swarm energy based on micro-grids proves to be more resilient and reliable than the central grid. Via their mobile phones, those who own their own PV systems can use the money they earn from selling electricity in real time. However, the success of these systems depends on the regulatory framework and the willingness of governments to consider decentralised energy as an acceptable alternative to the central grid and provide financing schemes for rural residents.

Klara Lindner's contribution on Mobisol's success story shows that start-ups operating in this difficult environment of rural, decentralised electrification need to be in control of the whole value chain - including devices such as TVs and mobile phone chargers, which they sell in conjunction with battery and rooftop solar - to ensure quality and reliability.

\section{New service and operating models}

Long before the liberalisation and privatisation of the electricity sector, companies specialised in service operations, optimisation, and the maintenance of energy installations, in particular in the area of building efficiency. The most prominent example is energy performance contracting (see also Burger \& Weinmann 2013 for a discussion). Since the 1970s, energy service companies have assisted utilities as sub-contractors to increase energy efficiency, typically based on energy audits. A new industry emerged that was able to deliver turnkey projects for large industrial and institutional customers (IFC 2007; Li, Qiu \& Wang 2014). According to the National Association of Energy Service Companies of the United States, the industry experienced a period of stagnation after the collapse of ENRON in the mid-2000s (IFC 2007: 9), but recovered soon afterwards. Based on a market survey by US company Navigant, the European Commission's Joint Research Council publishes estimates of the European 
market to be around $€ 2.4$ billion, with moderate growth of 1.7 per cent per year by 2024 (Boza-Kiss, Bertoldi \& Economidou 2017).

Business models in energy performance contracting may include the financing or leasing of assets, but typically the owner of the dwelling or industrial facility also owns the assets, which the contractor has installed, after the contracting period has ended.

As the increasing deployment of renewable energies leads to a more inelastic primary energy supply, it also becomes more attractive for companies, households, and utilities to increase their individual elasticity of demand and exploit financial opportunities related to fluctuations in wholesale market prices. Business models based on efficiency services and the optimisation of the operation of energy assets - including the equipment of dwellings, such as lighting and windows - require in-depth knowledge of the complex interplay of all the energy-related components of each object. With the use of practically unlimited computing power and artificial intelligence (AI) algorithms - also called machine learning - the barriers to entry in this field have been significantly reduced, and new players can more quickly and easily access the market than before. For example, MeteoViva is a start-up that uses local weather forecasts to optimise heating and cooling. The co-founder of Envio Systems has presented his company's business model in this book. He and his colleagues have developed a low-cost solution - compared to incumbent multinationals such as Johnson Controls, Schneider Electric, and Siemens - for retrofitting existing commercial and industrial buildings.

Not only new entrants, but also European energy utilities are moving towards service models. As in many other industries that are also moving from a 'technology push' to a 'market pull'. Customer-centricity has become a core element of their new strategies. For the electricity supply industry, this step is particularly challenging. Before liberalisation, residential customers were represented as standardised load profiles, anonymous numbers that could be easily aggregated, with minimal interaction occurring between the utility and user except for billing and meter readings. As regional monopolists, utilities did not have to take the differing preference sets of customer segments into account. With liberalisation, though, residential consumers started to become a relevant, non-negligible factor, since they could choose between different suppliers. Still, most utilities concentrated on defending their incumbent positions by offering differentiated tariff schemes adapted to each household's preferences. Most importantly, the cost and origin of electricity supply became the differentiating factors. Utilities realised that some customer segments were willing to pay a premium for climate-friendly primary energy sources, whereas other segments would choose primarily based on a comparison of costs per kilowatt hour.

The situation has fundamentally changed now. New entrants from other industries, in particular companies operating in information and communication technologies, such as Google, Apple, and telephony operators, have discovered electricity supply as a service they can provide in a package together 
with home automation, entertainment, as well as safety and security features. Building efficiency becomes part of a larger bundled service, for example with devices such as the intelligent thermostats provided by Nest and Tado, the manufacturers of heating, ventilation, and air-conditioning control systems equipped with - and linked to - machine learning algorithms, and aesthetically appealing as lifestyle gadgets. In early 2014, US company Google acquired Nest for US $\$ 3.2$ billion (Heisler 2016). Even though the acquisition might not have resulted in returns that would justify the high price tag, according to Heisler, Google's intention was to become a holistic service provider with access to energy consumption data and, more generally, the Smart Home.

Most of the pilot projects and large-scale field trials, which provide more complex services than the previous standard uniform tariffs, focus on differentiated electricity prices (day - night, weekdays - weekend, summer holidays - regular working weeks, or even more fine-grained differentiations of retail tariffs according to actual wholesale market prices). However, they have not yielded satisfactory results in terms of energy savings and residential demand shifts. Even the European Commission admits that residential consumers are only shifting 3 per cent of their demand when tariff schemes include a financial incentive to shift demand (European Commission 2018). Hence, business models that focus solely on shifting and optimising residential demand suffer from the fact that this type of demand is more inelastic than anticipated. The differences in tariffs simply do not provide a sufficiently rewarding incentive for consumers to change their habits when washing clothes, boiling water for tea, or baking a cake. Uniform tariffs are comparable to an insurance premium that residential consumers are willing to pay in order not to bother about the real (i.e. wholesale market) price of power. One has to bear in mind, though, these are very early days in terms of automation of household appliances, and it may get easier with new generations of white goods to access value at that granular level of residential, domestic consumption.

By contrast, service models that include other factors of convenience, such as making the home safer or allowing for assisted living, are more likely to attract the attention of customers. Utilities have realised that their expertise in these fields is limited. Even during liberalisation, their willingness to enter alliances was limited. They instead set up their proprietary business units, such as in trading, but now utilities have start establishing alliances. For example, German utility EnBW has founded a company called Qivicon, together with partners from telecommunications as well as white goods and Smart Home device manufacturers.

Service and operating models become attractive for a few reasons:

- Cash-strapped utilities may no longer have the financial leverage and shy away from investing in capital-intensive infrastructure, such as large-scale power plants. In addition, they fear stranded assets and the risks associated with an uncertain regulatory and market environment. 
- By contrast, they do have the expertise for providing services, at least in the field of energy, within their existing workforce. Often that type of human capital is dispersed across different business units, though, and has to become reorganised to provide a single point of contact for customers.

The less capital-intensive nature of these service-oriented business models makes it easier for new entrants and start-ups to enter the sector, too. The disruptive changes of digitalisation lower barriers to entry because hardware becomes less important than software, AI algorithms, and the customer interface.

Envio Systems is one example of a company that has utilised the hardwareas-a-service model, much like a marketing tool to attract cash-constrained customers to enter a service contract with them. Even though their payback period is substantially shorter than their high-end competitors, such as Siemens and Schneider Electric, the case of Envio Systems shows that the market for retrofitting existing buildings is still challenging.

Timo Leukefeld confirms this view. By contrast, his strategy is building and renting out new single-family and multi-story houses that are equipped with PV panels, solar thermal installations, a stationary battery, and a large water reservoir to store the heat. In this case, the configuration of the dwellings can be optimised according to the energy-efficiency standards. His practice cooperates with real estate developers, banks, and utilities. It is highly successful because tenants pay only slightly higher rents than in conventional houses. He believes in the 'flat rate society', where energy is part of a larger convenience package.

In the developing world, service and operating models are prospering, too. Solarkiosk has chosen a franchising approach of renting out its kiosks, because otherwise they would be too expensive for the shopkeepers in the countries they are targeting. It also leaves a maximum amount of autonomy to the operators of the kiosks - namely which products they want to sell and which services they offer - because the founders of the start-up believe that local residents would know best about the demand structure. Solarkiosk also shows that cooperations can be highly beneficial, as is the case with having Coca-Cola as a financial partner.

\section{New platform models}

Even before the liberalisation started, the electricity (and to some extent also natural gas) sector had some characteristics of a platform model: An entity - in most cases the grid operator, the utility, or a regional transmission operator was in charge of coordinating multiple generation units and power plants, which were sometimes owned by private operators. As opposed to grid operations, which are a critical part of the infrastructure with elements of a natural monopoly, liberalisation in the generation part of the value chain added wholesale markets as trading platforms. Organisations such as the European Energy Exchange in Leipzig, with its subsidiaries and partners all across Europe, are providers of the IT infrastructure, but neither own assets nor operate them. 
In Phase I of the energy transformation, they are the relevant references for buyers and sellers of energy, either directly or indirectly via brokers. When a country enters Phase II of the transformation, regulation often changes from fixed instruments such as feed-in tariffs to market-based mechanisms to compensate owners of renewable-energy assets. They have to develop their own strategies for how to earn money on the market, or they can shift that responsibility to aggregators. These companies typically offer a package of services to the owners that is centred around the timing and duration of operating the assets. They combine individual assets into virtual power plants. In Germany, Next Kraftwerke is the largest aggregator, combining a total of more than 6800 generation units, most of them renewable energies, with a capacity of almost 6 GW under its digital umbrella (as of February 2019).

This service is not limited to generation units. It can also integrate Demand Response for peak-shaving or ancillary grid services such as balancing energy, which become increasingly important when the share of renewable-energy intake rises above certain thresholds. Oliver Stahl, the founder and former CEO of the Demand Response solution provider Entelios, was interviewed for this book. His company not only aggregates and coordinates participants in the pool, but also offers this service to utilities that may not have the relevant expertise. In the interview, Stahl describes three major hurdles for Demand Response. The first is to make potential customers aware of the financial attractiveness of temporarily reducing their demand and gaining their confidence. Entelios picked one customer per industry sector as a role model in order to convince other players from the same sector. Second, not all industries are equally well-suited for Demand Response. In particular, the chemicals industry showed some hesitation because many processes are highly sensitive to fluctuations in energy supply. Third, becoming an integrated segment of a utility did not work because the representatives of the sales department - the most likely business unit to internally host a Demand Response provider - had an antagonistic incentive system and working culture.

In Europe, one of the largest companies offering Demand Response to commercial and industrial consumers is the Belgian start-up Restore, which targets the primary reserve and frequency control markets and operates in all ancillary services and capacity markets in Europe.

Some countries that have started moving from Phase II to Phase III of the transformation offer possibilities to establish peer-to-peer trading platforms. Australian start-up Power Ledger is one of them. Individuals can trade energy without interference from a utility as the intermediary. Depending on the regulatory context, these options are easier to implement in separate micro-grids, which are semi-detached from the central grid, because there is a higher degree of administrative autonomy.

Platform models have become very popular in many parts of the business world. Hospitality, accommodation, and transport services are offered that connect private individuals with other private individuals. Once energy 
services become largely decentralised, platforms may not only allow for trading, but also for more complex interactions. Australian start-up Power Ledger envisages smart demand and supply management, whole-market settlements, carbon trading, and even certain services in the management of transmission networks, such as network load-balancing, as future applications of its platform.

\subsubsection{Six core competencies for corporate decision makers}

How can corporate and political decision makers optimise their actions towards the transformation of the energy sector? The interviews with founders and entrepreneurs in the field of decentralised energy systems yielded important insights.

\section{Digitalisation}

The core competency that all industries are currently establishing is expertise in digitalisation - a theme that is present in all interviews - be it with artificial intelligence in the case of Envio Systems, the remote operating centres of Entelios, Mobisol, and SOLshare, or the blockchain-based application platform of Power Ledger. Beyond the capability of navigating in the digital sphere, the authors have identified five core competencies that will be decisive in tomorrow's decentralised energy markets.

\section{Customer centricity}

Customer centricity is an overarching, recurring theme in all of the interviews, which comes as no surprise, given that customers are coming into the focus of companies across almost all sectors.

Some of the start-ups presented in this chapter have customer-centricity within their corporate DNA. For example, demand-side management can only succeed if clients are treated individually in their energy-consumption and energy-savings patterns. Similarly, Envio Systems is developing a digital clone of each dwelling that is equipped with its Cubes, because retrofitting existing building stock requires a high degree of customisation - as opposed to building efficiency being implemented, for example, in greenfield real estate developments, where certain technological features can be replicated across all objects. Solarkiosk leaves it up to the operators of its kiosks as to which products and services they want to sell, since these people have a better understanding of the local context and the needs of future clients. Their approach combines the two worlds of charity projects with business ventures into a social enterprise. As Lars Krückeberg, co-founder of Solarkiosk, comments with regards to the context of developing countries, 'The combination of the two worlds is the only implementable option that allows for scalability'.

Other start-ups have developed standardised solutions but use a customercentric approach in refining their technologies and business models. For 
example, Klara Lindner reports that Mobisol developed a plug and play kit in co-creation sessions with real customers. Later they realised that their customers were not willing to do the installations by themselves, so they adapted their business model to accommodate that wish by hiring local village technicians, who would be in charge of the installations.

The core competency required in all these areas is not customer-centricity per se, but rather finding the balance between listening to users while ensuring a high degree of standardisation. Customer-centricity comes at a price, and the core competency required is to drive costs down by developing new forms of mass customisation.

\section{Financing and enabling of asset ownership}

Start-ups have developed diverse strategies for how they can help prosumers to finance decentralised generation assets. Especially in developing countries, the major hurdle of a large upfront investment has been removed; in rural settings, residential owners of rooftop solar systems can generate additional revenues for example by charging their neighbours' mobile phones or selling electricity on the micro-grid - to repay their debts, as the interviews with SOLshare and Solarkiosk and the contribution about Mobisol show. Start-ups use advanced transaction systems that are adapted to local markets, with the additional advantage of full transparency of money flows via apps on their mobile phones. For instance, SOLshare co-operates with bKash, currently the largest mobile money provider.

Financial competencies stretch into the sphere of cryptocurrencies. Australian start-up Power Ledger does not rely on Bitcoin, the most popular and widely known cryptocurrency, but enables transactions with a virtual currency called Spark, which consumers can use to purchase electricity or as producers to sell it. Power Ledger also spearheads the financing revolution in terms of crowdfunding and ICOs. In October 2017, Power Ledger raised more than €20 million through its token generation event. More than 15,000 buyers took part in Australia's first ICO.

\section{Technology leads and product innovation}

Despite the fact that the power supply industry is moving from product to service orientation, all start-ups have developed intellectual property in terms of product innovations. Envio Systems relies on its Cube, which is equipped with sensors like a $\mathrm{CO} 2$ sensor, to detect whether any person is actually present, and then uses proprietary artificial intelligence to optimise the consumption patterns of its clients. Mobisol works with its own direct current (DC) system, which is complemented by the household appliances of partner manufacturers running on DC. SOLshare produces its SOLbox and SOLcontrol devices directly in its workshops in Bangladesh. Solarkiosk developed and tested the containers that would later be transformed into kiosks under extreme climatic conditions in laboratories of the Beuth School of Applied Sciences in Berlin 
before the first kiosks were shipped to Africa. Power Ledger has built a proprietary IT architecture based on blockchain transaction protocols. Entelios also uses its own software to coordinate automatically the loads of its clients.

Technological advances and innovations give start-ups the leading edge and competitive differentiation. If companies rely on a pure service model, they can easily be crowded out by larger and financially stronger rivals.

\section{Partnerships and bundled services}

In a complex and highly dynamic market environment, no single company is able to provide all the elements of its value proposition by itself. Especially in the regulated world of utilities, which were the sole providers of energy, partnerships were not necessary because tariffs were a product of negotiations between suppliers and regulatory agencies or the government. Liberalisation has opened up the market to a range of combinations - packaged offers that may include entertainment, security, and individual transport in addition to core energy services. Consumers may enter, as Timo Leukefeld calls it, 'the flat rate society', where renting a house includes all turnkey solutions of convenience, plus free access to electric mobility. Leukefeld cooperates with real estate developers, banks, and utilities to build his dwellings. Energy is the trigger and remains an important element of his value proposition, but it is complemented by other products and services.

Similarly, Solarkiosk has teamed up with Coca-Cola, Ericsson, and Total. Envio Systems is seeking partners in major property management companies and with an elevator manufacturer. SOLshare has strong ties to Grameen Shakti, with whom it received the US\$1 million UN DESA Powering the Future We Want prize. The municipal utility of Munich became the first industry partner of Entelios and already signed a contract even before its founder, Oliver Stahl, had approached venture capitalists for additional financing. In its international expansion, Power Ledger has deals, for example, with BCPG, one of the largest solar IPPs in Thailand; Tech Mahindra in India; and the Liechtenstein Institute for Strategic Development, which will become the first application host to offer Power Ledger's blockchain-based peer-to-peer energy-trading platform in Europe.

With the increasing convergence of the energy and transport sectors, digitalisation affecting all aspects of our lives, and US tech giants entering energy markets, executives face no other option than to enter partnerships and alliances if they want to survive in the marketplace.

\section{Platforms/ecosystems}

Digitalisation allows multiple players to enter markets and match supply and demand. As companies such as Uber, Airbnb, and eBay have demonstrated in other sectors, ownership of physical assets may not be necessary to succeed in the marketplace. The value proposition is derived instead from the coordination of providers and seekers of certain services. Sometimes these markets do 
not exist and have to be established: Entelios triggered the market for Demand Response in Germany, as much as EnerNOC contributed to similar developments in the United States. Start-ups and cash-constrained utilities may seize the opportunity to provide the IT architecture to connect sellers and buyers, often with technologies that circumvent conventional routes.

Australian start-up Power Ledger has demonstrated with its token generation event that platform applications will change how the electricity supply industry functions, for example: peer-to-peer trading; smart demand and supply management with remuneration and payment settlements; management of consumer exposure to the risk of non-supply; collection of big data; Smart Contracts for carbon traders; management of transmission networks; network load-balancing; and power ports that allow electric vehicles to become mobile storage discharge facilities.

Many ecosystems do not yet exist, but those companies and governments that foresee their benefits and start with the implementation may be the winners in the energy world of the future.

\subsubsection{A world of entrepreneurial activity}

The business models of the seven start-ups that have been presented in this chapter are of course only a fragment of the wide spectrum of entrepreneurial activity that has emerged across the globe. Start-ups in all continents seize the opportunity of decentralisation to launch their ventures - some of them focusing on new business models with existing technologies, others developing new generation technologies or platforms. Innovation has moved from research labs and R\&D departments of manufacturers and utilities to a generation of young ventures - with digitalisation as the major driver for reducing barriers to entry.

As outlined in Section 3.1 of this chapter, the global energy transformation can be differentiated according to three distinct phases, which may vary and overlap across countries and regions. The next chapter summarises the insights from both regulatory conditions and business models within the respective phase.

\subsubsection{References}

Boza-Kiss, B., Bertoldi, P. \& Economidou, M. (2017), Energy service companies in the EU: status review and recommendations for further market development with a focus on energy performance contracting. EUR - Scientific and Technical Research Reports. Ispra: Joint Research Centre (JRC).

Bundesgeschäftsstelle Energiegenossenschaften. (2017), Die Genossenschaften in Deutschland. Retrieved November 24, 2017, from https://www. genossenschaften.de/bundesgesch-ftsstelle-energiegenossenschaften 
Burger, C. \& Weinmann, J. (2013), The decentralized energy revolution business strategies for a new paradigm. Basingstoke, UK: Palgrave Macmillan.

Burger, C., Kuhlmann, A., Richard, P. \& Weinmann, J. (2016), Blockchain in the energy transition. A survey among decision-makers in the German energy industry. Berlin: German Energy Agency dena/ESMT. Retrieved from https://shop.dena.de/sortiment/detail/produkt/studie-blockchain-in-derenergiewende/

BWE. (2017), Anzahl der Windenergieanlagen in Deutschland. Retrieved November 20, 2017, from https://www.wind-energie.de/infocenter/ statistiken/deutschland/windenergieanlagen-deutschland

DGRV. (2015), Energiegenossenschaften - Ergebnisse der DGRV-Jahresumfrage (zum 31.12.2014). Retrieved February 14, 2019, from https://www.dgrv.de/ de/news/news-2015.07.16-1.html\#

European Commission. (2018), Smart grids and meters. Retrieved March 7, 2018, from https://ec.europa.eu/energy/en/topics/markets-and-consumers/ smart-grids-and-meters

Gassmann, O., Frankenberger, K. \& Csik, M. (2014), The business model navigator: 55 models that will revolutionise your business. London: Pearson/ Financial Times.

Hamwi, M. \& Lizarralde, I. (2017), A review of business models towards service-oriented electricity systems. Procedia CIRP, 64, 109-114.

Heisler, Y. (2016), Google's Nest acquisition was more disastrous than we thought. BGR. Retrieved November 30, 2017, from http://bgr.com/2016/06/06/ googles-nest-acquisition-was-more-disastrous-than-we-thought/

IFC. (2007), Introduction to energy performance contracting, National Association of Energy Services Companies. Retrieved February 11, 2019, fromhttps:// www.energystar.gov/ia/partners/spp_res/Introduction_to_Performance_ Contracting.pdf

Li, Y., Qiu, Y. \& Wang, Y.D. (2014), Explaining the contract terms of energy performance contracting in China: The importance of effective financing. Energy Economics, 45(C), 401-411.

Orcutt, M. (2017), What the hell is an initial coin offering? Cambridge, MA: MIT Technology Review.

Perea, A. (2017), Q3 2017 Update: the state of distributed solar. GTMresearch. Retrieved February 11, 2019, from http://www.ncsl.org/Portals/1/Documents/ energy/webinar_A_Perea_9_2017_31661.pdf

Power Ledger. (2017), Power Ledger token generation event. Retrieved November 27, 2017, from https://powerledger.io/

St. John, J. (2017), Blockchain energy trading startup Power Ledger raises \$17M in cryptocurrency 'ICO' GTM Research. Retrieved February 11, 2019, from https://www.greentechmedia.com/articles/read/power-ledger-blockchainenergy-trading-startup-raises-17-cryptocurrency\#gs.u0lJtXV5 
Stock, P., Stock, A. \& Bourne, G. (2017), State of solar 2016: globally and in Australia, Climate Council. Retrieved February 11, 2019, from https://www. climatecouncil.org.au/resources/solar-report/

Thomsen, S. (2017), Australia's first initial coin offering raises $\$ 34$ million. Business Insider Australia. Retrieved February 11, 2019, from https://www. businessinsider.com.au/australias-first-initial-coin-offering-has-raised34-million-2017-10 